\title{
Unanchored Ubiquitin Chains, Revisited
}

\author{
Jessica R. Blount ${ }^{1}$, Sean L. Johnson ${ }^{1}$ and Sokol V. Todi ${ }^{1,2 *}$ \\ ${ }^{1}$ Department of Pharmacology, Wayne State University School of Medicine, Detroit, MI, United States, ${ }^{2}$ Department \\ of Neurology, Wayne State University School of Medicine, Detroit, MI, United States
}

The small modifier protein, ubiquitin, holds a special place in eukaryotic biology because of its myriad post-translational effects that control normal cellular processes and are implicated in various diseases. By being covalently conjugated onto other proteins, ubiquitin changes their interaction landscape - fostering new interactions as well as inhibiting others - and ultimately deciding the fate of its substrates and controlling

\section{OPEN ACCESS}

Edited by:

Mauro Salvi,

University of Padua, Italy

Reviewed by:

Ricardo Rajsbaum,

University of Texas Medical Branch

at Galveston, United States

Yohei Yamauchi,

University of Bristol, United Kingdom

Robert Layfield,

University of Nottingham,

United Kingdom

${ }^{*}$ Correspondence:

Sokol V. Todi

stodi@wayne.edu

Specialty section:

This article was submitted to

Cellular Biochemistry,

a section of the journal

Frontiers in Cell and Developmental

Biology

Received: 13 July 2020

Accepted: 15 September 2020

Published: 26 October 2020

Citation:

Blount JR, Johnson SL and Todi SV (2020) Unanchored Ubiquitin

Chains, Revisited.

Front. Cell Dev. Biol. 8:582361.

doi: 10.3389/fcell.2020.582361 pathways that span most cell physiology. Ubiquitin can be attached onto other proteins as a monomer or as a poly-ubiquitin chain of diverse structural topologies. Among the types of poly-ubiquitin species generated are ones detached from another substrate - comprising solely ubiquitin as their constituent - referred to as unanchored, or free chains. Considered to be toxic byproducts, these species have recently emerged to have specific physiological functions in immune pathways and during cell stress. Free chains also do not appear to be detrimental to multi-cellular organisms; they can be active members of the ubiquitination process, rather than corollary species awaiting disassembly into mono-ubiquitin. Here, we summarize past and recent studies on unanchored ubiquitin chains, paying special attention to their emerging roles as second messengers in several signaling pathways. These investigations paint complex and flexible outcomes for free ubiquitin chains, and present a revised model of unanchored poly-ubiquitin biology that is in need of additional investigation.

Keywords: poly-ubiquitin, cell stress, deubiquitinase, immune system, NF-кB, proteasome, ligase, protein quality control

Abbreviations: CARD, caspase activation and recruitment domain; DUB, deubiquitinating enzyme; E1, Ub activating enzyme; E2, Ub conjugating enzyme; E3, Ub ligase enzyme; HDAC6, histone deacetylase 6; HECT, Homologous to the E6AP Carboxyl Terminus; HIV-1, human immunodeficiency virus 1; IAV, Influenza A virus; IFN, interferon; IFN-I, type I interferon; IKK, IkB kinase; IL-1R, IL-1 receptor; IRAK-1, IL-1R-associated kinase 1; IRF3, interferon regulatory factor 3; IRF7, interferon regulatory factor 7; ISG, interferon-stimulated genes; ISGF3, interferon-stimulated gene factor 3; JAK1, Janus kinase 1; JAMM, JAB1/MPN/MOV34 metalloenzyme; MAVS, mitochondrial activator of virus signaling; MEFs, mouse embryonic fibroblasts; MINDY, motif interacting with Ub-containing novel DUBs family; NEMO, NF-kB essential modulator; OTU, ovarian tumor protease; RBR, RING-Between-RING; RING, Really Interesting New Gene; RLR, RIG-I-like receptor; STAT1, signal transducer and activator of transcription 1; TAB1, TAK1-binding protein 1; TAB2, TAK1-binding protein 2; TAK1, transforming growth factor b-activated kinase 1; TBK1, TANK-binding kinase 1; TLR, Toll like receptor; TNFR, tumor necrosis factor receptor; TRAF6, TNFR-associated factor 6; TYK2, Tyrosine kinase 2; Ub, ubiquitin; UBAN, Ub binding in ABIN and NEMO; UCH, Ub C-terminal hydrolase; USP, Ub-specific protease; ZnF-UBP, zinc-finger Ub-binding domain; ZUFSPs, zinc-finger with UFM1-specific peptidase domain proteins. 


\section{AN INTRODUCTION TO UBIQUITIN, ITS PROCESSING, AND UNANCHORED CHAINS}

Few proteins hold as central a place in eukaryotic cellular biology as the highly conserved, 76-residue protein, ubiquitin (Ub). Through a chemical reaction that enables its tethering onto essentially any other protein, Ub provides exceptionally flexible control over processes from cell division to cell death, from gene transcription to protein degradation, by dictating protein interaction, function, and turnover (Komander and Rape, 2012; Swatek and Komander, 2016; Oh et al., 2018). It is not surprising that, because of its elemental importance in eukaryotes, Ub and the pathways that it regulates are linked to various diseases.

Ub's modulatory properties commonly begin with the process of "ubiquitination," which refers to the ATP-dependent conjugation of a $\mathrm{Ub}$ molecule onto a substrate protein via an isopeptide bond between the C-terminal carboxylic group of a $\mathrm{Ub}$ and the $\varepsilon$-amine of a lysine residue within the substrate. The cellular machinery that brings about this conjugation consists of three main components: a Ub-activating enzyme (E1), a Ubconjugating enzyme (E2), and a Ub ligase (E3). A protein that has accepted a single Ub molecule is said to be mono-ubiquitinated; additional ubiquitination can result in a multi-ubiquitinated protein decorated with individual $\mathrm{Ub}$ molecules (Figure 1A). Following a mono-ubiquitination event, the conjugated Ub can also be ubiquitinated itself, forming a polymeric chain (Figures 1A,B). Each Ub harbors seven lysine residues (Lys6, 11, $27,29,33,48$, and 63) that themselves serve as Ub acceptor sites, spread over the surface of the protein and oriented in distinct directions. In addition, an eighth ubiquitination site exists at the N-terminal methionine (Met1) (Komander and Rape, 2012).

Poly-Ub chains are characterized by the Lys or Met residue used for chain elongation and can be composed of homogenous linkages (e.g., a tri-Ub chain with only Lys48 linkages; Figure 1B); multiple linkage types within a continuous chain (Figure 1C); or branched chains, where a Ub chain attached to a second string of poly-Ub leads to topology that resembles branches on a tree (Figure 1D). Linkage type also determines the conformation and flexibility of the chain - while Met1- and Lys63-linked chains adopt open conformations with more space between Ub molecules, Lys6-, Lys11-, and Lys48-linked poly-Ub are more compact, according to structural studies (Tenno et al., 2004; Varadan et al., 2004). The Lys48- and Lys63-linked chains diagrammed in Figure 1B illustrate the basic difference between compact and open conformations.

The shape of a Ub chain affects its binding partners, as some proteins are attracted by the pockets created by specific linkage types (Hicke et al., 2005; Dikic et al., 2009). This binding landscape gains even greater complexity through mixedlinkage and branched chains and through additional posttranslational modifications to $\mathrm{Ub}$, including phosphorylation (Yau and Rape, 2016; Song and Luo, 2019). Two poly-Ub chains that contain the same linkage types can behave in unique ways, depending on the arrangement of those linkages, the chains' proximity to post-translational modifiers that act upon them, and the accessibility to Ub-binding proteins that bind specific chain types to direct them to signaling pathways or organelles (Oh et al., 2018).

The composition of a poly-Ub chain and the context of its attachment to a substrate can trigger different outcomes in the cell. (Table 1 summarizes functions of poly-Ub chains of each linkage type and enzymes reported to construct, edit, or dismantle them.) Some Ub chains target proteins to the $26 \mathrm{~S}$ proteasome for degradation, where the poly-Ub chain is removed to be recycled whereas the protein conjugated to it is unfolded and degraded. Lys48-linked chains are the most abundant linkage with this role, although Lys11-, Lys29-, and in some cases Lys63-linked chains, have also been implicated in this functional degradation pathway (Thrower et al., 2000; Bremm and Komander, 2011; Besche et al., 2014). Branched Lys11/Lys48-linked Ub chains have also emerged as an enhanced degradation signal vital to both cell-cycle regulation and in the quality control of aggregation-prone proteins (Meyer and Rape, 2014; Yau et al., 2017). Lys48/Lys63-linked, branched chains are another degradation signal that associates with the proteasome (Ohtake et al., 2018).

In addition to proteasomal degradation, mono-Ub and Lys63linked chains target plasma membrane proteins to lysosomes for degradation (Mukhopadhyay and Riezman, 2007; Chen et al., 2019; Gomez-Diaz and Ikeda, 2019). One type of lysosomal degradation, macro-autophagy (hereafter referred to as autophagy), is induced by cellular stress and is marked by the formation of cytoplasmic, double-membrane vesicles that envelop damaging cellular components, including protein aggregates and damaged organelles. These autophagic vesicles, called autophagosomes, fuse with lysosomes to degrade and recycle their contents. Autophagy involves $\mathrm{Ub}$ at several steps. For example, autophagy-inducing factors are regulated by ubiquitination; Lys63 poly-Ub promotes their stability and induces autophagy (Nazio et al., 2013; Xia et al., 2013), while Lys48 poly-Ub targets them to the proteasome and inhibits autophagy (Xia et al., 2014; Xu et al., 2014). Similar ubiquitination events control the genesis and maturation of autophagosomes by promoting the degradation, stabilization, or interactions of various autophagy factors (Joachim et al., 2017; Feng et al., 2019; Gu et al., 2019; Scrivo et al., 2019). Mitophagy, the selective autophagy of damaged mitochondria, is dependent on the E3 Parkin's Lys6, Lys11, Lys48, and Lys63-linked poly-ubiquitination of the mitochondrial outer membrane (Harper et al., 2018). Although ubiquitination is most commonly associated with the proteasome, its importance to other degradative pathways is also well-established.

Outside of degradation, ubiquitination coordinates the recruitment of various proteins to participate in signaling pathways, alters protein localization by attracting trafficking factors, and even regulates the conformation and activity of the substrate itself (Komander and Rape, 2012; Swatek and Komander, 2016; Oh et al., 2018; Clague et al., 2019). These nondegradation pathway functions are typically, but not exclusively, associated with mono-Ub, Met1-, and Lys63-linked chains (Table 1). Furthermore, chains can induce non-degradative regulation of protein activity indirectly. Met1-, mixed Lys11/ Lys63-, Lys63-, and Lys48-linked chains can regulate pathway 


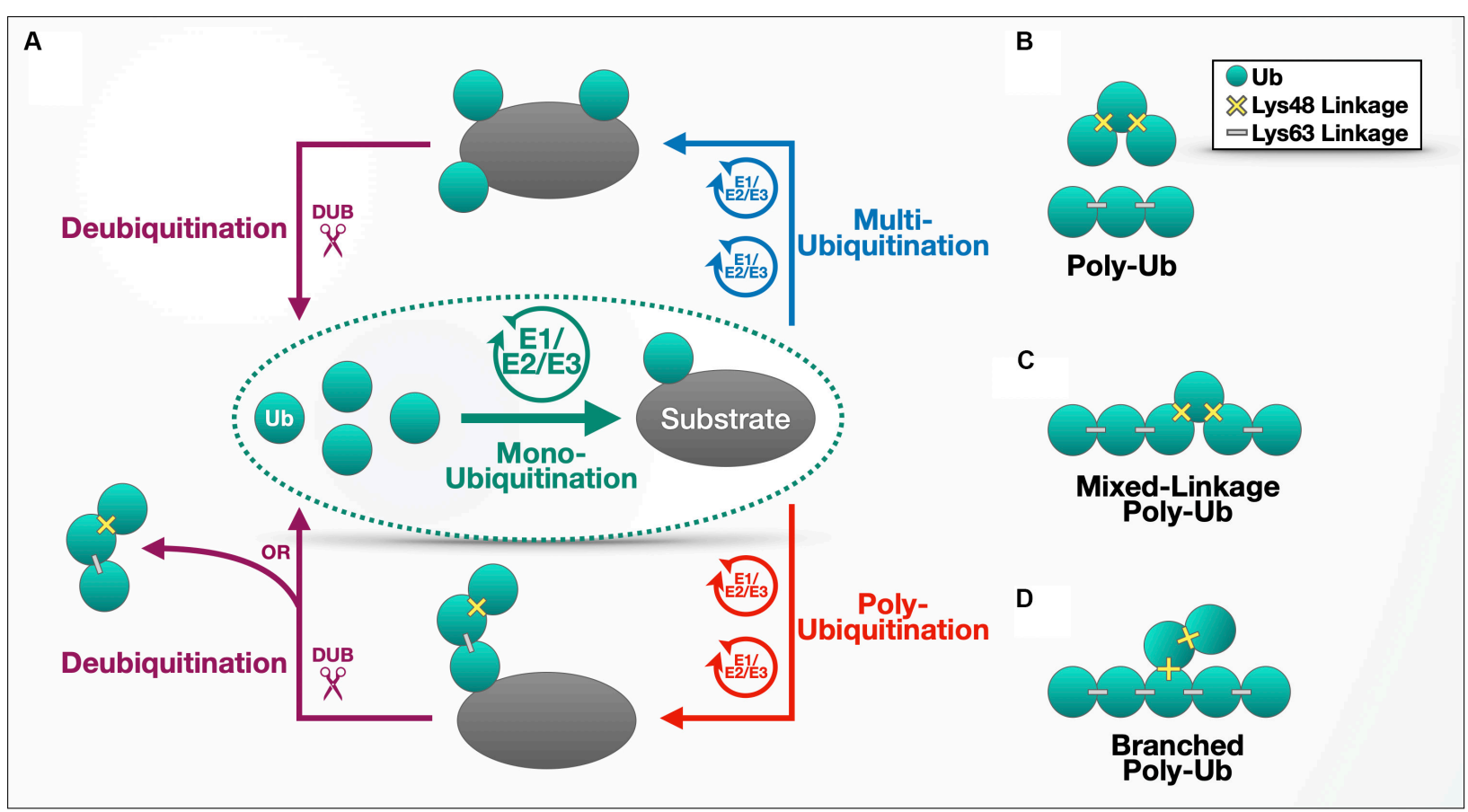

FIGURE 1 | The ubiquitination process. (A) Outline of the ubiquitination process. (B-D) Different types of ubiquitin chains. Details are provided in the main text.

signaling through inhibitor degradation, allosteric activation as a result of structural reordering, or the recruitment of activating enzymes (Komander and Rape, 2012; Swatek and Komander, 2016; Oh et al., 2018; Clague et al., 2019; Table 1). These various topologies and the nearly limitless types of Ub conjugation that can occur are responsible for the many processes controlled by $\mathrm{Ub}$ and the numerous diseases linked to it, from malignancies to neurological diseases and afflictions of the immune system.

Decades of research have been dedicated to the study of ubiquitination, yet it often seems that we have only begun to understand its countless functions in the cell and the players that direct Ub's roles. What specifies which proteins are ubiquitinated, and with what type of chain? Determinants of substrate specificity include the E2 and E3 enzymes involved (Table 1). A ubiquitination event is initiated when the E1 activating enzyme hydrolyzes ATP and forms a thioester bond with $\mathrm{Ub}$. The $\mathrm{Ub}$ is then passed to an E2 conjugase through a transthiolation reaction. An E3 ligase then facilitates the formation of an isopeptide bond between $\mathrm{Ub}$ and a lysine in its target protein. How this final step happens depends on the type of E3 involved.

Ub ligases are classified into three families based on constituent domains and Ub transfer mechanisms: RING, HECT, and RBR. RING (Really Interesting New Gene) E3s, the most abundant type, serve as scaffolds to enable the direct transfer of $\mathrm{Ub}$ from the E2 to the target protein. HECT (Homologous to the E6AP Carboxyl Terminus) E3s transfer Ub in two steps: a transthiolation event moves the $\mathrm{Ub}$ molecule from the E2 to the E3, before passing it to the substrate. RBR (RING-BetweenRING) E3s also work in distinct steps: a RING domain recruits a Ub-charged E2, a RING-like domain forms a thioester bond with the $\mathrm{Ub}$, and the $\mathrm{Ub}$ is subsequently transferred to the substrate. While the human genome contains only two E1 Ub-activating enzymes, there are $\sim 40$ E2 conjugases and more than 600 E3 ligases that can contribute to substrate and linkage specificity. HECT and RBR E3s each determine the types of Ub linkages they create, while RING E3s depend on their cooperating E2 to impart that specificity (Christensen and Klevit, 2009; Komander and Rape, 2012).

Once a Ub chain has been formed on a substrate, it can be removed or edited by deubiquitinating enzymes (DUBs). Humans have $\sim 100$ DUBs, some of which have preferences for chain type, length, and location, while others are promiscuous in those regards (Table 1). DUBs are divided into seven sub-families: Ub-specific proteases (USPs), Ub C-terminal hydrolases (UCHs), ovarian tumor proteases (OTUs), Machado-Joseph disease proteases (MJDs), JAB1/MPN/MOV34 metalloenzymes (JAMMs), motif interacting with Ub-containing novel DUB family (MINDYs), and zinc-finger with UFM1specific peptidase domain proteins (ZUFSPs). USPs, UCHs, OTUs, MJDs, MINDYs, and ZUFSPs are cysteine proteases, whereas JAMMs are zinc metalloproteases (Clague et al., 2012, 2019; Abdul Rehman et al., 2016; Kwasna et al., 2018).

The significance of DUBs is evident from the beginning of a Ub molecule's existence, as Ub genes are transcribed as peptide-linked tandem repeats ( $U B B$ and $U B C$ gene products) or as ribosomal fusion proteins (UBA52 and RPS7A gene products) that require processing by DUBs before they can be 
TABLE 1 | Summary of cellular processes associated with specific types of Ub linkages, and some of the E2s, E3s, and DUBs associated with them. (List not exhaustive; additional enzymes covered in main text.)

\begin{tabular}{|c|c|c|c|c|}
\hline & \multirow[t]{2}{*}{ Reported cellular processes } & \multirow[t]{2}{*}{ Abundance } & \multirow{2}{*}{$\begin{array}{l}\text { E2s and E3s reported } \\
\text { Bold: linkage-specific }\end{array}$} & \multirow{2}{*}{$\begin{array}{l}\text { DUBs reported } \\
\text { Bold: } \\
\text { linkage-specific }\end{array}$} \\
\hline & & & & \\
\hline Lys6 & $\begin{array}{l}\text { Mitochondrial homeostasis } \\
\text { - Mitophagy delayed in cells with mutant Lys6 Ub } \\
\text { (Cunningham et al., 2015; Ordureau et al., 2015) } \\
\text { - Involved with mitochondrial homeostasis (Durcan } \\
\text { et al., 2014; Ordureau et al., 2014, 2015; } \\
\text { Cunningham et al., 2015) } \\
\text { - Observed on ubiquitinated mitochondrial } \\
\text { membrane proteins after mitochondrial } \\
\text { depolarization (Ordureau et al., 2014) } \\
\text { DNA damage response } \\
\text { - Regulates DNA damage response with the E3 } \\
\text { BRCA1/BARD1 (Wu-Baer et al., 2003; Morris and } \\
\text { Solomon, 2004; Nishikawa et al., 2004) }\end{array}$ & $\begin{array}{l}\text { - Does not increase with protease inhibition (Kim } \\
\text { et al., 2011; Wagner et al., 2011) } \\
\text { - Increases upon UV-based genotoxic stress (Elia } \\
\text { et al., 2015) } \\
\text { - Increases in response to mitochondrial } \\
\text { depolarization (Ordureau et al., 2014) }\end{array}$ & $\begin{array}{l}\text { E2 } \\
\text { - No specific E2s reported } \\
\text { E3 } \\
\text { - Bacterial HECT-like E3 (Lin et al., 2011) } \\
\text { - N1eL (Hospenthal et al., 2013) } \\
\text { - BRCA1/BARD1 (Wu-Baer et al., 2003; Morris and } \\
\text { Solomon, 2004; Nishikawa et al., 2004) } \\
\text { - Parkin (Durcan et al., 2014; Ordureau et al., 2014; } \\
\text { Cunningham et al., 2015) }\end{array}$ & $\begin{array}{l}\text { - USP30 (localized to } \\
\text { mitochondria) (Bingol } \\
\text { et al., 2014; } \\
\text { Cunningham et al., } \\
\text { 2015; Liang et al., } \\
\text { 2015) }\end{array}$ \\
\hline Lys11 & $\begin{array}{l}\text { Cell cycle regulation } \\
\text { - Triggers proteasomal degradation of cell cycle } \\
\text { regulators during mitosis (Jin et al., 2008; } \\
\text { Williamson et al., 2009; Matsumoto et al., 2010; } \\
\text { Bremm and Komander, 2011; Wickliffe et al., 2011; } \\
\text { Castańeda et al., 2013; Meyer and Rape, 2014) } \\
\text { Proteasomal degradation } \\
\text { - Homotypic Lys11-linked chains are typically poor } \\
\text { substrates for the proteasome (Matsumoto et al., } \\
\text { 2010; Bremm and Komander, 2011; Wickliffe et al., } \\
\text { 2011; Castańeda et al., 2013; Meyer and Rape, } \\
\text { 2014; Grice et al., 2015) } \\
\text { - The E2 UBE2S and E3 APC/C construct branched } \\
\text { chains comprising Lys11 that are strong } \\
\text { proteasomal degradation signals, as well as } \\
\text { heterotypic Lys11/Lys48-linked chains (Meyer and } \\
\text { Rape, 2014; Grice et al., 2015; Min et al., 2015) } \\
\text { Other } \\
\text { - Implicated in cell-cycle-independent processes: } \\
\text { • Hif1(alpha) transcription factor } \\
\text { (Bremm et al., 2014); ERAD (Xu et al., 2009b); } \\
\text { innate immune response (Qin et al., 2014); } \\
\text { cellular adaptation to hypoxia } \\
\text { (Bremm et al., 2010; Moniz et al., 2015) }\end{array}$ & $\begin{array}{l}\text { - Increases in response to proteasome inhibition (Xu } \\
\text { et al., 2009b; Kim et al., 2011) } \\
\text { - Increases in response to mitochondrial } \\
\text { depolarization (Ordureau et al., 2014) } \\
\text { - Preferentially produced during mitosis and G1 in } \\
\text { cells (Xu et al., 2009a; Matsumoto et al., 2010; } \\
\text { Meyer and Rape, 2014) }\end{array}$ & $\begin{array}{l}\text { E2 } \\
\text { - Ube2S (Baboshina and Haas, 1996; Jin et al., 2008; } \\
\text { Garnett et al., 2009; Williamson et al., 2009; Wu et al., } \\
\text { 2010; Wickliffe et al., 2011; Min et al., 2015) } \\
\text { - Ube2C/UbcH10 (Kirkpatrick et al., 2006; Jin et al., 2008; } \\
\text { Bosanac et al., 2011) } \\
\text { E3 } \\
\text { - APC/C (Baboshina and Haas, 1996; Jin et al., 2008; } \\
\text { Garnett et al., 2009; Williamson et al., 2009; Wu et al., } \\
\text { 2010; Min et al., 2015) } \\
\text { - Parkin (Sarraf et al., 2013; Durcan et al., 2014; Ordureau } \\
\text { et al., 2014; Cunningham et al., 2015) } \\
\text { - UBR5 (Yau and Rape, 2016) } \\
\text { - AREL1 (Kristariyanto et al., 2015b; Michel et al., 2015; } \\
\text { Swatek and Komander, 2016) }\end{array}$ & $\begin{array}{l}\text { - OTUD7B (Mevissen } \\
\text { et al., 2013) } \\
\text { - Cezanne2/OTUD7A } \\
\text { (Mevissen et al., 2013) } \\
\text { - USP30 (Cunningham } \\
\text { et al., 2015) }\end{array}$ \\
\hline
\end{tabular}


TABLE 1 | Continued

Reported cellular processes

\section{Abundance}

DNA damage (Gant type on chromatin fowing

DNA damage (Gatti et al., 2015)

- The E3 ligase RNF168 promotes ubiquitination

histone 2A, the major form of ubiquitination on

chromatin following DNA damage (Gatti et al., 2015)

- Serves as scaffolding to recruit DNA damage

response mediators (Liu et al., 2014a; Gatti et al.,

2015)

- Lack of Lys27-linked chains prevents activation of

DNA damage response (Gatti et al., 2015)

Immune response

- Associated with the host immune response in

response to microbial DNA (Ishikawa et al., 2009;

Wang et al., 2014b)

- Lys27-linked poly-Ub of STING acts as a scaffold

for the recruitment and activation of the kinase

TBK1 (Ishikawa et al., 2009; Wang et al., 2014b).

This association triggers a cascade that leads the

activation of transcription factor IRF-3 and induction

of type- 1 interferons and pro-inflammatory

cytokines (Ishikawa et al., 2009; Wang et al.,

2014b)

\section{Lys29 Proteasomal degradation}

- Associates with the 26S proteasome and

contributes to substrate turnover in the

Ub-fusion-degradation pathway (Johnson et al.,

1995; Koegl et al., 1999; You and Pickart, 2001;

Besche et al., 2014)

Repression of $\mathrm{Wnt} / \beta$-catenin signaling

- Lys29-linked poly-Ub of Axin disrupts its interaction

with co-receptors and represses Wnt/ $\beta$ signaling

(Fei et al., 2013)

\section{Lys33 Post-Golgi membrane trafficking}

- Implicated in regulating traffic through the

post-Golgi network (Yuan et al., 2014)

Other

- Associated with negative regulation of T-cell antigen

receptor (Huang et al., 2010)

- Associated with negative regulation of

AMPK-related protein kinases (Al-Hakim et al.

2008)
- Increases upon inhibition of the proteasome (Kim et al., 2011

- Increases upon UV-based genotoxic stress (Elia et al., 2015)
DUBs reported

Bold:

linkage-specific

Bold: linkage-specific

- None reported

No specific E2s reported

E3

- Parkin (Doss-Pepe et al., 2005; Geisler et al., 2010)

- AMFR (Ishikawa et al., 2009; Wang et al., 2014b)

- RNF168 (Gatti et al., 2015)

- HACE1 (Liu et al., 2014b; Palicharla and Maddika, 2015)
E2

- None reported

- KIAA10/UBE3C (You and Pickart, 2001; Wang and Pickart, 2005; Wang et al., 2006; Kristariyanto et al., 2015a; Michel et al., 2015)

- UBR5 (Yau and Rape, 2016)

- UFD4 (Tsuchiya et al., 2013)

E2

- None reported

E3

CUL3 (Yuan et al., 2014)

- AREL1 (Kristariyanto et al., 2015b; Michel et al., 2015;

Swatek and Komander, 2016)
- TRABID (Swatek and Komander, 2016)

- TRABID (Swatek and Komander, 2016) 
- Targets proteins to the 26S proteasome for degradation (Chau

Lu et al., 2015)

Other

- Involved with Wnt signaling propagation (Tauriello and Maurice

2010)

- Indirectly regulates protein activity by signaling the degradation of various inhibitors (Winston et al., 1999; Margottin-Goguet et al.,

2003)

- Can impair protein interactions without triggering degradation (Flick et al., 2006)

- Role in innate immune response signaling (Rajsbaum et al., 2014; Hage and Rajsbaum, 2019)

\section{Lys63 Scaffolding to facilitate protein interactions}

- Acts as an interaction point for the formation and activation of various complexes and pathways:

- Activation of NF-kB transcription factor (Deng et al., 2000;

Wang et al., 2001; Xia et al., 2009; Xu et al., 2009a)

- DNA repair (Spence et al., 1995; Hoege et al., 2002;

Sobhian et al., 2007; Doil et al., 2009; Huang et al., 2009;

Stewart et al., 2009; Al-Hakim et al., 2010)

- Innate immune responses (Gack et al., 2007)

- Mitophagy (Cunningham et al., 2015; Ordureau et al., 2015)

- Protein sorting (Lauwers et al., 2009; Huang et al., 2013)

- Assembly of protein complexes that drive mRNA splicing and

translation (Spence et al., 2000; Bellare et al., 2008;

Song et al., 2010; Silva et al., 2015)

- Propagation of Wnt signaling (Tauriello and Maurice, 2010)

Lysosomal degradation

- Targets substrate to the lysosome for degradation (Mukhopadhyay

and Riezman, 2007; Raiborg and Stenmark, 2009; Ren and Hurley, 2010)

- Serves as an interaction point for adaptor molecules of

autophagosomes and substrates en route to lysosoma

degradation (Kirkin et al., 2009)
- Predominant linkage type in cells, often

E2

$50 \%$ of all linkages (Xu et al., 2009b;

Dammer et al., 2011; Kim et al., 2011

Wagner et al., 2011; Ziv et al., 2011)

- Levels increase upon proteasome inhibition

(Xu et al., 2009b)

- Increases in response to mitochondria

depolarization (Ordureau et al., 2014)

Ube2K (Petroski and Deshaies, 2005; Christensen et al., 2007 ; Kim et al., 2007; Rodrigo-Brenni et al., 2010; Rajsbaum et al.,

$$
\text { 2014) }
$$

- Ube2G2 (Li et al., 2007)

- Ubc1 (Petroski and Deshaies, 2005; Christensen et al., 2007; Rodrigo-Brenni et al., 2010)

- Ube2R1/Cdc34 (Petroski and Deshaies, 2005; Li et al., 2007:

Rodrigo-Brenni et al., 2010; Sadowski et al., 2010)

- Ube2D (Wang and Pickart, 2005; Kim and Huibregtse, 2009) E3

- BRCA1/BARDI (Christensen et al., 2007; Kim et al., 2007)

- SCF (Petroski and Deshaies, 2005)

- AMFR (Chen et al., 2006; Li et al., 2007)

- E6AP (Scheffner et al., 1993; Wang and Pickart, 2005; Kim and

Huibregtse, 2009)

- KIAA10/UBE3C (Sloper-Mould et al., 2001)

- Bacterial HECT-like E3 (Lin et al., 2011)

- Parkin (Doss-Pepe et al., 2005; Geisler et al., 2010)

- N1eL (Hospenthal et al., 2013)

- AREL1 (Michel et al., 2015)

- UFD2 (Saeki et al., 2004)

- TRIM6 (Rajsbaum et al., 2014)

Second most abundant chain type, after Lys48 (Chen and Sun, 2009)

E2

Ube2N/Uev1a/Ubc13 (Zhang et al., 2005; Eddins et al., 2006; - Levels increase in response to mitochondrial Christensen et al., 2007; Kim et al., 2007; Xia et al., 2009) depolarization (Ordureau et al., 2014)

- Ube2D (Kim and Huibregtse, 2009; Maspero et al., 2011)

E3

BRCA1/BARD1 (Christensen et al., 2007; Kim et al., 2007)

- CHIP (Zhang et al., 2005)

- TRIM5 (Pertel et al., 2011)

- TRIM21 (McEwan et al., 2013)

TRIM25 (Zeng et al., 2010)

- RSP5/Nedd4 (Richly et al., 2005; Kim and Huibregtse, 2009; Maspero et al., 2011)

- TRAF6 (Cao et al., 1996; Deng et al., 2000; Xia et al., 2009)

- Parkin (Doss-Pepe et al., 2005; Geisler et al., 2010;

Cunningham et al., 2015)
- CYLD (Zeng et al., 2010; Sato et al., 2015)

- AMSH (Swatek and Komander, 2016)

- $\mathrm{POH} 1$ (Hao et al., 2013)
- OTUB1 (Swatek

2016)

USP5/ISOT

Reyes-Turcu et al. 2008) 
TABLE 1 | Continued

\begin{tabular}{|c|c|c|c|c|}
\hline & \multirow[t]{2}{*}{ Reported cellular processes } & \multirow[t]{2}{*}{ Abundance } & \multirow{2}{*}{$\begin{array}{l}\text { E2s and E3s reported } \\
\text { Bold: linkage-specific }\end{array}$} & \multirow{2}{*}{$\begin{array}{l}\text { DUBs reported } \\
\text { Bold: linkage-specific }\end{array}$} \\
\hline & & & & \\
\hline Met1 & $\begin{array}{l}\text { NF-kB signaling } \\
\text { - Modifies the IKK complex subunit NEMO in order to } \\
\text { allosterically activate IKK in the NF-kB pathway } \\
\text { (Rahighi et al., 2009; Tokunaga et al., 2009; } \\
\text { Gerlach et al., 2011; Ikeda et al., 2011; Tokunaga } \\
\text { et al., 2011; Damgaard et al., 2012) } \\
\text { Other } \\
\text { - Cytokine signaling } \\
\text { - Regulation of interferon production (Inn et al., 2011) } \\
\text { - Control of Wnt signaling during blood vessel } \\
\text { formation (Rivkin et al., 2013) }\end{array}$ & $\begin{array}{l}\text { - Rapidly synthesized in response to activation of } \\
\text { inflammatory signaling cascades (Tokunaga and } \\
\text { Iwai, 2009; Gerlach et al., 2011; Ikeda et al., 2011; } \\
\text { Tokunaga et al., 2011) }\end{array}$ & $\begin{array}{l}\text { E2 } \\
\text { - Ube2K (Tokunaga and Iwai, 2009; Tokunaga et al., 2009; } \\
\text { Ikeda et al., 2011; Tokunaga et al., 2011) } \\
\text { E3 } \\
\text { - LUBAC (Kirisako et al., 2006; Rahighi et al., 2009; } \\
\text { Tokunaga and Iwai, 2009; Tokunaga et al., 2009; Gerlach } \\
\text { et al., 2011; Ikeda et al., 2011; Tokunaga et al., 2011) }\end{array}$ & $\begin{array}{l}\text { CYLD (Sato et al., 2015) } \\
\text { - OTULIN (Swatek and } \\
\text { Komander, 2016) }\end{array}$ \\
\hline Mono-Ub & $\begin{array}{l}\text { Mediates protein interaction } \\
\text { • Can impair protein interactions: } \\
\text { • Mono-Ub of Smad4 blocks its association with } \\
\text { Smad2 (Dupont et al., 2009) } \\
\text { • Blocks interactions of adaptor proteins to } \\
\text { cargo in EGFR signaling (Polo et al., 2002; } \\
\text { Hoeller et al., 2006, 2007) } \\
\text { • Recruits enzymes to specific cellular locations in } \\
\text { response to DNA damage (Hoege et al., 2002; } \\
\text { Bienko et al., 2005, 2010; Nijman et al., 2005; } \\
\text { Huang et al., 2006; Moldovan et al., 2007; } \\
\text { Moldovan and D'Andrea, 2009; Freudenthal et al., } \\
\text { 2010; Huang and D'Andrea, 2010; Joo et al., } \\
\text { 2011): } \\
\text { • PCNA, FANCD2, and FANCl are all } \\
\text { mono-Ub-d and also involved in DNA repair } \\
\text { pathways (Hoege et al., 2002; } \\
\text { Bienko et al., 2005, 2010; Nijman et al., 2005; } \\
\text { Huang et al., 2006; Moldovan et al., 2007; } \\
\text { Moldovan and D'Andrea, 2009; } \\
\text { Freudenthal et al., 2010; } \\
\text { Huang and D'Andrea, 2010; Joo et al., 2011) } \\
\text { Lysosomal degradation } \\
\text { • Targets substrates to the lysosome for degradation } \\
\text { (Mukhopadhyay and Riezman, 2007) }\end{array}$ & $\begin{array}{l}\text { - Reduced in response to proteasome inhibition, } \\
\text { most likely in favor of polyubiquitin chain formation } \\
\text { (Kaiser et al., 2011) } \\
\text { - Levels vary among tissue, cell, and model types. It } \\
\text { is the most abundant, conjugated form of ubiquitin } \\
\text { and may rival levels of free mono-ubiquitin (Kaiser } \\
\text { et al., 2011) }\end{array}$ & $\begin{array}{l}\text { E2 } \\
\text { - Ube2D (Wang et al., 2004; Bentley et al., 2011) } \\
\text { - UbcH5 (Wang et al., 2004; Bentley et al., 2011) } \\
\text { - Ube2A (Hoege et al., 2002; Hwang et al., 2010; Hibbert } \\
\text { et al., 2011) } \\
\text { - Ube2W (Machida et al., 2006; Christensen et al., 2007; Alpi } \\
\text { et al., 2008; Scaglione et al., 2011) } \\
\text { - Ube2T (Machida et al., 2006; Alpi et al., 2008) } \\
\text { E3 } \\
\text { - BMI1-RING1 (Wang et al., 2004; Bentley et al., 2011) } \\
\text { - Rad18 (Hoege et al., 2002; Hwang et al., 2010; Hibbert } \\
\text { et al., 2011) } \\
\text { - FANCL (Machida et al., 2006; Alpi et al., 2008) } \\
\text { - BRCA1/BARD1 (Christensen et al., 2007; Scaglione et al., } \\
\text { 2011) } \\
\text { - CHIP (Christensen et al., 2007; Scaglione et al., 2011) } \\
\text { - Parkin (Chew et al., 2011) } \\
\text { - CUL3 (Jin et al., 2012; Werner et al., 2015) }\end{array}$ & - None reported \\
\hline
\end{tabular}


used as mono-Ub for substrate ubiquitination (Clague et al., 2012; Komander and Rape, 2012). DUBs also serve as negative regulators of Ub signaling; for example, a protein with a Lys48linked tetra-Ub chain attached as a proteasomal targeting signal can be spared of degradation by a DUB that removes that chain (Clague et al., 2013, 2019). The $26 \mathrm{~S}$ proteasome itself contains and is closely associated with DUBs that recognize Ub chains and remove them from degradation-bound proteins to be reused for novel ubiquitination events (Komander et al., 2009; Liu et al., 2015; Clague et al., 2019). Finally, DUBs participate in poly-Ub editing to change the length or composition of the chain, thus modifying the substrate protein's fate or participation in specific pathways (Komander et al., 2009; Clague et al., 2013, 2019). Some DUBs partner with E3 ligases to attach new Ub molecules, and there is even a DUB that has E3 activity itself, the NF- $\kappa B$ modulator, A20 (Wertz et al., 2004).

DUBs can disassemble chains one molecule at a time [e.g., UCH37 (Lam et al., 1997)], or they can remove the entire chain at once (Figure 1A, bottom left), resulting in unanchored, or free, poly-Ub that is not attached to a substrate protein. An example of the latter type of DUBs, USP14, removes en bloc poly-Ub chains from multi-poly-ubiquitinated cyclin B (a cell cycle regulator) until only one chain remains attached, reducing cyclin B's interaction with the proteasome and thus effectively inhibiting its degradation in vitro (Lee et al., 2016). Another DUB, the proteasome resident POH1, is a zinc-dependent metalloprotease that cleaves poly-Ub from substrates, saving the chain from degradation, and yielding unanchored poly-Ub (Yao and Cohen, 2002).

Unanchored Ub chains make their first appearance in the cell at the time of $\mathrm{Ub}$ gene transcription, as human $U B B$ and $U B C$ encode three and nine tandem repeat $\mathrm{Ub}$, respectively. Transcription of these genes results in linear, unanchored polyUb that is processed by DUBs that have zinc-finger Ub binding domains (Znf-UBPs) that specifically recognize the chains' free C-termini, including USP3, USP4, and USP16 (Clague et al., 2019). In mammals, $U B B$ and $U B C$ transcription is upregulated during cellular stress, when increased signaling requires an ample supply of Ub (Fornace et al., 1989). Unanchored poly-Ub can also be assembled anew by specialized E2/E3 pairs in vitro and in cells. This type of production is observed when the E3 TRIM6 and the E2 UbE2K generate unanchored, Lys48-linked Ub chains that activate an interferon (IFN) signaling component (Rajsbaum et al., 2014). Moreover, as mentioned above, en bloc removal of a Ub chain from a substrate, or cleavage of a poly-Ub branch from a branched chain, in total or in part, also yields unanchored poly-Ub.

The study of free poly-Ub is relatively new, and we have only begun to understand their complicated nature. They are commonly thought of as potentially toxic competitors at the proteasome, and their rapid disassembly is thought to be essential to cellular health and Ub homeostasis. However, untethered Ub chains are also directly implicated in specific pathways, including NF-KB-related processes; thus, their presence in the cell is clearly important. Yeast and in vitro studies suggested that unanchored poly-Ub inhibit normal proteasomal function and are toxic, whereas Drosophila studies more recently indicated that they are tolerated in an intact, multi-cellular organism. For the remainder of this review, we examine the details and complexities of unanchored Ub chains.

\section{CASES OF TOXICITY FROM UNANCHORED UBIQUITIN CHAINS}

Much of our knowledge of unanchored poly-Ub arose from research on the best-known DUB that processes it, Ubspecific protease 5 (USP5). Mammalian USP5 (also known as isopeptidase T) was first purified from reticulocytes in 1985 (Pickart and Rose, 1985) and later characterized as an enzyme that preferentially disassembles poly-Ub species after they are removed from ubiquitinated substrates at the $26 \mathrm{~S}$ proteasome (Hadari et al., 1992). USP5 specifically recognizes the free C-terminal diglycine (GG) motif of untethered poly-Ub and removes Ub monomers sequentially from the chain's proximal end (Wilkinson et al., 1995). Kinetic assays revealed that $\mathrm{Ub}$, itself, can modulate USP5 activity in vitro: low Ub concentrations activate USP5, whereas partial inhibition is observed at higher Ub concentrations (Stein et al., 1995).

USP5 contains four Ub-binding domains that cooperate to recognize and process multiple types of unanchored poly$\mathrm{Ub}$, with a preference for Lys48-linked chains (Reyes-Turcu et al., 2008). Its ZnF-UBP domain governs USP5's specificity for untethered chains, with a specialized pocket that recognizes the unencumbered C-terminus of the proximal Ub (Reyes-Turcu et al., 2006). In the fruit fly, Drosophila melanogaster, USP5 knockdown or null mutation is developmentally lethal (Tsou et al., 2012; Wang et al., 2014a; Kovacs et al., 2015; Ristic et al., 2016). One proposed purpose for USP5 is to maintain a pool of available mono-Ub by cleaving untethered poly-Ub; when USP5 cannot perform this function, the cell would then lack the building blocks necessary for normal ubiquitination. However, toxicity from RNAi knockdown of USP5 in the fruit fly was not alleviated by over-expression of mono-Ub (Ristic et al., 2016); thus, toxicity arising from reduced or absent activity of USP5 cannot be explained solely by a disruption of mono-Ub supply, and may involve dysregulation of specific ubiquitinated substrates (García-Caballero et al., 2014, 2016).

When Ub is properly folded, several hydrophobic amino acid residues converge to form a hydrophobic surface that serves as the interaction site for many Ub-binding domains (Deveraux et al., 1994; Beal et al., 1996, 1998). It is through this hydrophobic patch that substrate-conjugated poly-Ub binds S5a, a subunit of the regulatory compartment of the $26 \mathrm{~S}$ proteasome, allowing proteasome-resident and -associated DUBs to detach the chain and enhance the degradation of the targeted protein (Deveraux et al., 1994; Beal et al., 1996). Could unanchored Ub chains directly cause toxicity by binding to the proteasome in lieu of ubiquitinated substrates, interrupting normal proteolysis? Using reconstituted reticulocyte proteasome complexes to study USP5 function in vitro, Hadari et al. (1992) determined that USP5 stimulates the proteolysis of poly-ubiquitinated substrates. If unanchored Ub chains can outcompete ubiquitinated substrates at the proteasome and hinder normal proteolysis, the authors suggested that USP5 prevents this by quickly disassembling 
chains - as soon as they are removed from their substrates - thus enhancing proteolysis by removing competition (Hadari et al., 1992). In this study, the authors did not perform binding assays to assess competition between unanchored chains and ubiquitinated substrates at the proteasome, instead focusing on the effect of USP5 on in vitro proteolysis and inferring a corresponding effect from unprocessed poly-Ub.

In follow-up studies, Piotrowski et al. (1997) synthesized Lys48-linked, untethered poly-Ub of various lengths (from $\mathrm{Ub}^{2}$ to $\mathrm{Ub}^{8}$ ) and examined their effects on in vitro proteasomal function. The authors found that $\mathrm{Ub}$ chain length dictates the magnitude of proteasomal inhibition and the chain's affinity for the proteasome: longer chains are more likely to bind and more strongly inhibit the proteasome (Piotrowski et al., 1997). Later, Thrower et al. (2000) identified $\mathrm{Ub}^{4}$ as the minimum signal for efficient proteasomal degradation and showed that unanchored chains compete with ubiquitinated substrates to bind to purified, mammalian proteasomes, again in an in vitro setting.

In vivo studies in yeast support the notion that unanchored poly-Ub can inhibit proteasomal activity. When Amerik et al. (1997) deleted the UBP14 gene encoding the USP5 ortholog in Saccharomyces cerevisiae cells, they observed accumulation of unanchored $\mathrm{Ub}$ chains and inhibition of the Ub-dependent, proteasomal degradation of MAT $\alpha 2$, L- $\beta$ gal, and Ub-P- $\beta$ gal, reporter proteins used to study Ub-dependent protein turnover. Reasoning that free Ub chains may be the culprits hampering proteasomal degradation, they expressed in wild-type yeast cells a Ub mutant lacking the $\mathrm{C}$-terminal diglycine residues required for Ub's conjugation onto other proteins and its recognition by UBP14. This mutant (Ub $\Delta \mathrm{GG}$ ) can be ubiquitinated, allowing for the creation of unanchored, UBP14-resistant poly-Ub with the mutant Ub molecule at the end (Amerik et al., 1997). (Similar mutants that lack an intact C-terminal "GG" motif are used in studies described below; although the precise amino acid mutations vary, the effect is the same, and all such mutants are referred to as " $\mathrm{Ub} \Delta \mathrm{GG}$ " throughout this review.) Yeast cells expressing Ub $\Delta \mathrm{GG}$ mutants suffer growth defects, sensitivity to environmental stressors, and a reduction in overall protein degradation (Ecker et al., 1987; Hodgins et al., 1992). The presence of unanchored, Ub $\Delta \mathrm{GG}$ chains coincided with reduced proteolysis of MAT $\alpha 2$ and Ub-P- $\beta$ gal, again indicating proteasomal dysfunction in vivo, in a single cellular organism (Amerik et al., 1997).

Moving beyond purified proteasomes and yeast studies, Dayal et al. (2009) linked USP5 to unanchored chain disassembly in a mammalian cellular system. From a screen of DUBs affecting the activity of the tumor suppressor, p53 in cultured, ARN8 human melanoma cells, the authors found that knockdown of USP5 stabilizes and activates p53. They also observed by Western blotting an increase in low molecular weight Ub species that migrate at the same molecular weight as purified, free Lys48linked chains, and concluded that these are unanchored Ub species induced by USP5 suppression. Expression of Ub $\Delta \mathrm{GG}$ recapitulated the effects of USP5 knockdown in ARN8 cells, leading to increased p53 activity. USP5 siRNA or Ub $\Delta$ GG expression also caused increased ubiquitination of p53. Since this increased ubiquitination, which could be a degradation signal, counter-intuitively coincides with slowed p53 turnover, the authors argued that the effects of USP5 suppression on p53 activity are mediated by the accumulation of unanchored $\mathrm{Ub}$ chains that outcompete ubiquitinated p53 at the proteasome and extend its half-life (Dayal et al., 2009); the study did not directly examine whether p53 ubiquitination is consistent with a degradation signal, or whether its binding to the proteasome is impaired in the presence of mutant $\mathrm{Ub}$.

Ultimately, various studies (Hadari et al., 1992; Amerik et al., 1997; Piotrowski et al., 1997; Thrower et al., 2000; Dayal et al., 2009) on unanchored poly-Ub pointed toward a toxic effect, often linked to inhibition of the proteasome and the buildup of proteins that were destined to be degraded. We note that these investigations were performed using in vitro systems, a singlecell organism, or cultured mammalian cells; there remains a potential for free Ub chains to behave differently in cells in vivo and in multicellular organisms. Ub itself is highly conserved and enzymes that dictate its use, editing, and recycling are also conserved at several levels. But, there is also a significant expansion in the number and types of Ub-related proteins and enzymes with evolutionary progression, leaving open the possibility that free Ub chains may have different roles and be regulated differently among species.

\section{UNANCHORED CHAINS AND THEIR PHYSIOLOGICAL ROLES IN IMMUNITY}

Beyond their potential for toxicity, untethered Ub chains have been implicated as participants in specific cellular pathways, which we discuss below. Their inclusion in these pathways is evidence that free poly-Ub species are not exclusively toxic, but that they also have important physiological roles in regulating immune pathways that guard against invading pathogens and control inflammatory responses (Figures 2-5).

\section{TAK1 and IKK Activation}

Just as USP5 studies uncovered the potential for untethered poly-Ub to inhibit the proteasome in some systems, much of our knowledge of the normal functions of free Ub chains came to us originally from investigations into Ubc13/Uevla, an E2 complex that generates unanchored poly-Ub (Xu et al., 2008). Ubc13/Uevla is important for innate immunity, as it is required for intracellular NF- $\mathrm{kB}$ signaling that originates with interleukin1 receptors (IL-1Rs) and Toll-like receptors (TLRs) (Deng et al., 2000; Wang et al., 2001).

IL-1 cytokines in humans, including IL- $1 \beta$, are small, proinflammatory proteins that bind IL-1Rs on the cell's surface (Figure 2). IL-1 $\beta$ binding to IL-1R causes the receptor to form a complex that includes IL-1R-associated kinase 1 (IRAK-1) and the E3 ligase (tumor necrosis factor receptor) TNFR-associated factor 6 (TRAF6). IRAK-1 and TRAF6 dissociate from IL-1R, and TRAF6 joins transforming growth factor $\beta$-activated kinase 1 (TAK1), TAK1-binding protein 1 (TAB1) and TAB2 in a new complex in the cytoplasm. Activated TAK1 phosphorylates another cytoplasmic complex, the IKB kinase (IKK) complex, consisting of two catalytic subunits (IKK $\alpha$ and IKK $\beta$ ) and a regulatory subunit (IKK $\gamma / \mathrm{NF}-\kappa \mathrm{B}$ essential modulator, known as NEMO). The IKK complex then phosphorylates I $\mathrm{B} \alpha$, resulting 


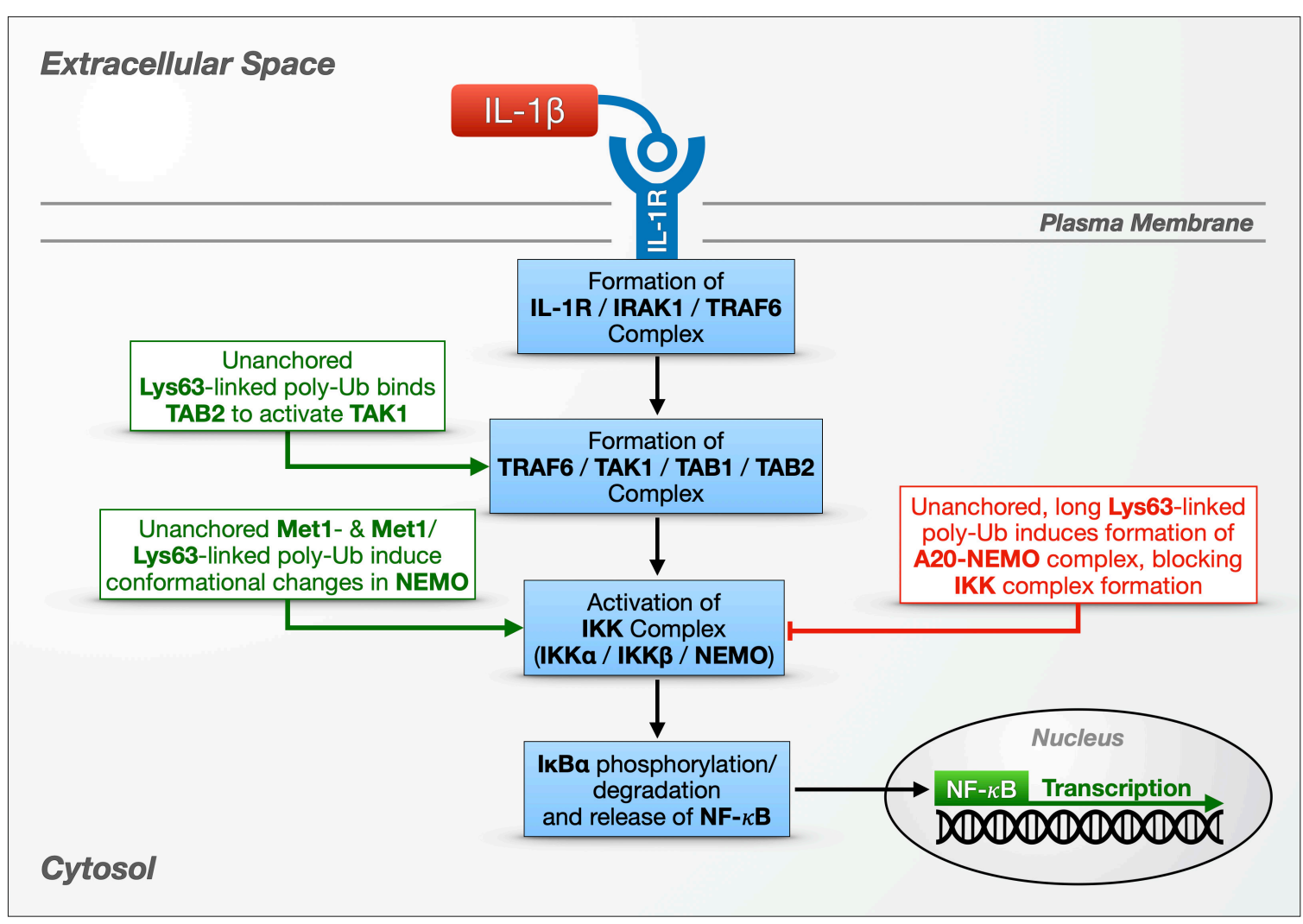

FIGURE 2 | Unanchored poly-ubiquitin in IL-1R signaling. Multiple types of unanchored chains play a role in innate immunity and the NF- $\kappa B$ signaling pathway

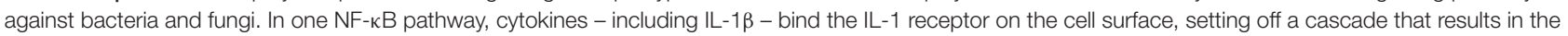
activation and nuclear translocation of NF-кB transcription factors. Additional details are provided in the main text.

in its proteasomal degradation and the nuclear translocation of the freed NF-кB proteins (Figure 2; Chen and Chen, 2013; Courtois and Fauvarque, 2018).

Xia et al. (2009) were the first to ascribe a physiological function to unanchored poly-Ub by directly implicating unanchored, Lys63-linked Ub chains in the activation of TAK1 and, by extension, in the activation of a canonical NF- $\kappa$ B pathway. At the time, it was known that Ubc13/Uevla is required for TAK1 to phosphorylate the IKK complex (Deng et al., 2000; Wang et al., 2001), but the mechanism was unclear. The authors reconstituted TAK1 activation using purified components and found that unanchored, Lys63-linked poly-Ub generated by Ubc13/Uev1a and TRAF6 triggered the phosphorylation and activation of TAK1 in vitro (Xia et al., 2009). Moving to cultured cells, the authors used IL-1 $\beta$ to stimulate HEK-293 cells that stably express IL-1R (termed stable IL-1R cells) and immunoprecipitated the TAK1 complex using TAB2 antibody. The kinase complex co-immunoprecipitated with endogenous, USP5-sensitive (suggesting unanchored) poly-Ub, which they then purified for in vitro experiments. The presence of these poly-Ub species activated TAK1 in vitro by binding TAB2 at its Npl14 zinc-finger Ub-binding domain, inducing TAK1 phosphorylation. Furthermore, USP5-sensitive poly-Ub species generated by Ubc13/Uevla and Ubc5, which can make various Ub chain types, beyond Lys63-linked species, activated the IKK complex via NEMO's Ub-binding domain. The authors proposed a model by which unanchored, Lys63-linked chains bind TAB2 and draw together two TAK1 complexes that mutually phosphorylate and activate one another, while other types of untethered chains bind and activate NEMO in the IKK complex (Figure 2).

What type of poly-Ub activates NEMO has been a complicated question to address. NEMO contains a Ub-binding domain, the $\mathrm{Ub}$ binding in ABIN and NEMO (UBAN) domain, that is required for NF- $\kappa \mathrm{B}$ activation in mouse embryonic fibroblasts (MEFs) (Rahighi et al., 2009). UBAN can interact with both anchored and unanchored Ub chains, and although it preferentially binds linear poly-Ub with as few as two Ub, longer chains with different linkage types also bind NEMO in vitro and in cultured cells (Laplantine et al., 2009; Rahighi et al., 2009; Dynek et al., 2010; Kensche et al., 2012). In stable, IL-1R HEK-293T cells, IL-1 $\beta$ treatment stimulates the production of Lys63-linked poly-Ub decorated with Met1-linked poly-Ub, i.e., branched chains (Emmerich et al., 2013). NEMO can bind these heterotypic chains, based on immunoprecipitation experiments, but it was unclear whether any of the associated poly-Ub species were unanchored. Other in vitro studies showed that covalent, Met1-linked di-ubiquitination of NEMO activates the IKK complex more potently than unanchored, Met1-linked $\mathrm{Ub}^{2}$, but longer poly-Ub chains were not tested. Spectroscopy 
studies suggested that NEMO's interactions with other proteins are mediated by long, linear poly-Ub chains: binding of Met1linked $\mathrm{Ub}^{10}$ induces a conformational change in NEMO that promotes its association with IKK $\beta$ and I $\mathrm{I} \mathrm{B} \alpha$ in vitro (Catici et al., 2015). It seems that Ub-dependent NEMO activity can be mediated by both substrate-conjugated and untethered poly-Ub, and the magnitude of the effect may depend on chain length, linkage composition, and the type of interaction or bond.

Untethered Ub chains have also been linked to the negative regulation of $\mathrm{NF}-\kappa \mathrm{B}$ through their interaction with $\mathrm{A} 20$, a dual function enzyme with an N-terminal OTU DUB domain and seven $\mathrm{ZnF}$ domains, and with $\mathrm{E} 3$ activity at its C-terminus (Wertz et al., 2004). A20 suppresses NF- $\kappa$ B activity in the TNFR and TLR pathways by editing poly-Ub attached to various mediators and by disrupting the assembly of E2/E3 Ub enzyme complexes (Wertz et al., 2004; Shembade et al., 2010). Skaug et al. (2011) discovered an additional, non-catalytic mechanism for A20 suppression of NF- $\kappa$ B activity that depends on unanchored $\mathrm{Ub}$ chains. Through in vitro experiments including GST pulldowns, Ub-binding assays, and cell-free IKK activation systems, the authors showed that A20 can form a complex with NEMO and long (six or more), untethered, Lys63-linked Ub chains, which then prevents IKK activation. Formation of this complex in vitro is aided by long, unanchored chains. Lys63-, Lys48-, and Met1linked $\mathrm{Ub}^{4}$ had no effect; long chains with linkage types other than Lys63 were not tested. Overexpression and RNAi-based studies using HeLa S100 cell extracts confirmed the formation of an A20-NEMO complex, dependent on TRAF6, Ubc13, and A20's ZnF7 Ub-binding domain. The authors concluded that IL-1 $\beta$ binding to IL1R promotes the assembly of unanchored, Lys63-linked Ub chains by TRAF6 and Ubc13/Uev1a, which then recruit the TAK1 and IKK complexes via Ub-binding domains in TAB2 and NEMO. If A20 is present, it outcompetes TAB2 for poly-Ub binding, and poly-Ub becomes the scaffold in a complex with A20 and NEMO. Formation of this complex inhibits IKK phosphorylation by TAK1, thereby blocking NF- $\kappa$ B signaling (Figure 2).

The studies summarized above (Rahighi et al., 2009; Xia et al., 2009; Skaug et al., 2011; Catici et al., 2015) provide strong evidence that unanchored poly-Ub species contribute to mammalian innate immune responses to bacteria and fungi by modulating at least two steps within NF- $\kappa B$ pathways: (1) the activation of the IKK complex (via TAK1) to phosphorylate I $\mathrm{B}$ and free NF- $\kappa \mathrm{B}$ transcription factors, and (2) the termination of TNFR- and TLR-regulated NF- $\kappa$ B signaling by A20 (Figure 2). Collectively, they underscore important roles for free poly-Ub in normal eukaryotic cell physiology.

\section{RIG-I and IFN-I Pathway Activation}

Innate immunity also protects organisms against viruses. A complete virus particle, or a virion, consists of viral DNA or RNA surrounded by a protein shell called a capsid. After entering a host cell, the virion's capsid is removed and the genetic material is released into the cytosol. Host cell organelles replicate the viral genome and assemble new virions that are released into the extracellular space to infect new cells. Viruses provoke specific immune responses in their hosts, sometimes relying on NF- $\kappa$ B pathways. Human immunodeficiency virus 1
(HIV-1), which causes AIDS, activates NF- $\kappa \mathrm{B}$ signaling through TRIM5, an E3 ligase. Interaction with the HIV-1 capsid stimulates TRIM5 to synthesize free Lys63-linked chains that activate TAK1, increasing NF- $\mathrm{B}$ activity to fight the infection (Pertel et al., 2011). Another E3, TRIM21, also produces unanchored Lys63linked poly-Ub to activate TAK1 in the presence of antibodybound pathogens in the cytosol (McEwan et al., 2013).

In a separate immune pathway, RIG-I-like receptors (RLRs) detect viral RNA in the cytosol of an infected cell and initiate a signaling cascade that culminates in the production of antiviral molecules including IFNs (Figure 3). Transcription factors involved in this antiviral response include NF- $\kappa$ Bs, interferon regulatory factor 3 (IRF3), and IRF7. In contrast to NF- $\kappa B$ proteins, which are activated by the degradation of their inhibitor I $\mathrm{B} \alpha$, IRF3 and IRF7 are activated by direct phosphorylation by the non-canonical IKKs, IKK $\varepsilon$ and TANK-binding kinase 1 (TBK1), which causes the transcription factors to dimerize and translocate to the nucleus (Paz et al., 2006; Loo and Gale, 2011).

RIG-I is an RLR expressed at low levels in the cytoplasm of most human cells. When RIG-I detects double-stranded viral RNA, an ATP-dependent dimerization and conformation change is triggered, exposing two tandem, $\mathrm{N}$-terminal caspase activation and recruitment domains (CARDs). These CARDs interact with a CARD on the $\mathrm{N}$-terminus of the signaling adaptor protein mitochondrial activator of virus signaling (MAVS), which in turn activates IKK $\varepsilon$ and TBK1 to phosphorylate IRF3 and IRF7 (Figure 3; Paz et al., 2006; Loo and Gale, 2011).

To study Ub-dependent mechanisms involved in RIG-I signaling, Zeng et al. (2010) developed a cell-free model of viral infection that combines purified RIG-I protein, mitochondrial and cytosolic extracts, RNA, and ubiquitination enzymes, using IRF3 dimerization as a reporter for RIG-I and MAVS activity. Viral or engineered RNA was used to activate RIG-I in cytosolic extracts, which stimulates MAVS in mitochondrial extracts to promote the dimerization of IRF3. The authors determined that Lys63-linked, unanchored Ub chains are potent, direct activators of RIG-I in vitro, binding its tandem CARD domains after RIG-1 detects viral RNA (Figure 3). The authors also verified the presence of this $\mathrm{Ub}$ chain type in a human cell line by devising a method to immunoprecipitate endogenous, free polyUb from HEK-293T cells using recombinant RIG-I N-terminus [GST-RIG-I(N)]. Some poly-Ub species that bind GST-RIG$\mathrm{I}(\mathrm{N})$ formed $\beta$-mercaptoethanol-sensitive thioester bonds with E1 Ub-activating enzyme, indicating a free C-terminus, and were sensitive to both USP5 and the Lys63-specific DUB, CYLD, leading the authors to identify them as unanchored, Lys63-linked chains. The endogenous poly-Ub isolated by this method potently activated IRF3 dimerization in the cell-free system, and their expression was induced by viral infection of HEK-293T cells. TRIM25 is at least partially responsible for producing these Ub chains, as siRNA targeting this E3 ligase diminished Lys63-linked, free poly-Ub levels in HEK-293T cells; conversely, CYLD siRNA led to higher levels, indicating a negative regulatory role for the DUB.

In later studies, Jiang et al. (2012) expanded on these findings by using the reconstituted RIG-I activation assay introduced above to demonstrate that non-covalent binding of free, Lys63-linked Ub chains to RIG-I's CARD domains 


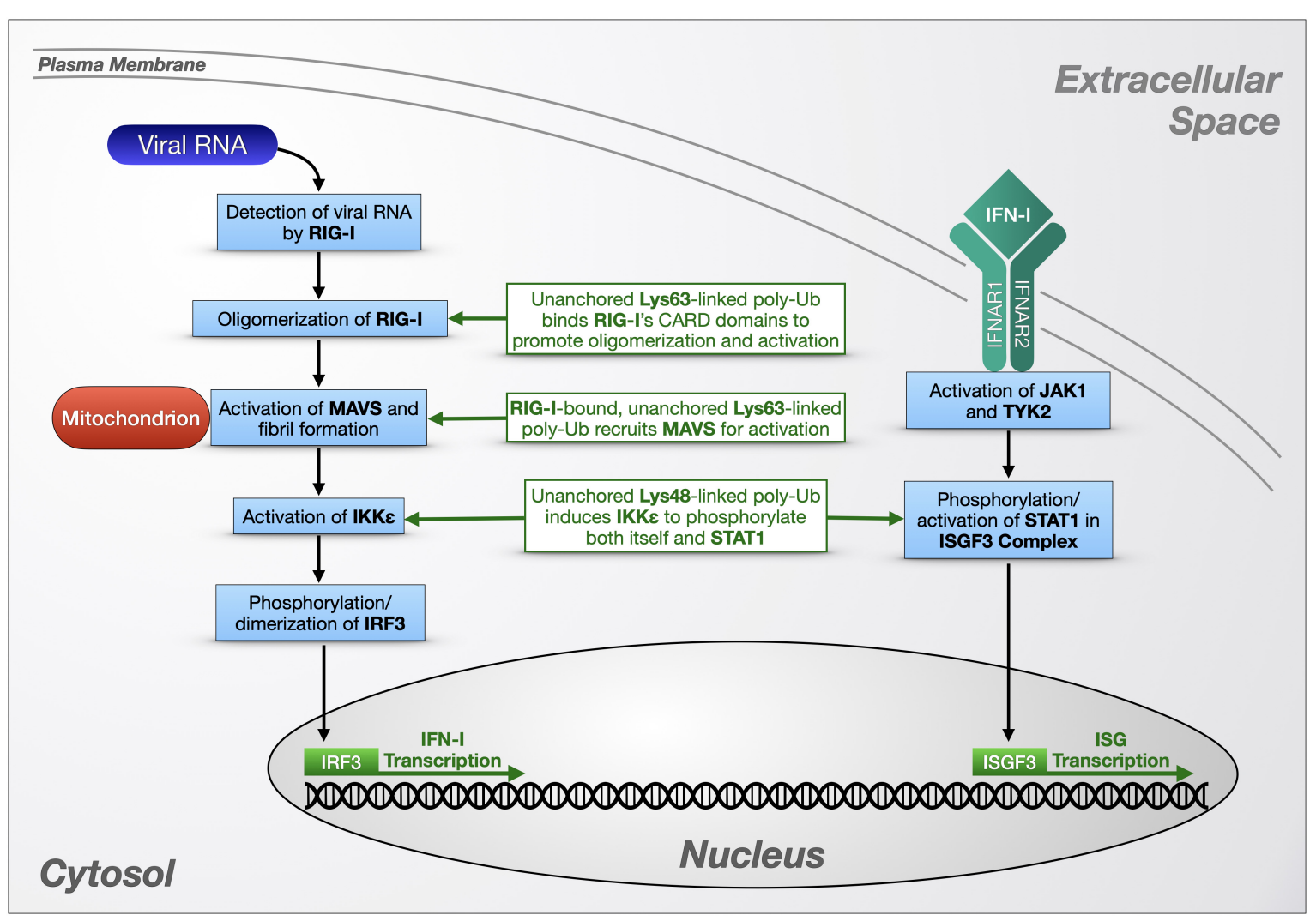

FIGURE 3 | Unanchored poly-ubiquitin in RLR signaling. Unanchored ubiquitin chains play a role in the cellular response to viral RNA via RIG-1 and IFN-I-dependent pathways. RIG-I-like receptors (left portion) detect cytosolic viral RNA and initiate a signaling cascade that triggers the production of antiviral molecules such as interferons (IFNs; right portion) that themselves can initiate additional transcriptional responses to viral presence. Detailed information on these pathways is provided in the main text.

promotes its oligomerization (Figure 3). Sedimentation velocity analytical ultracentrifugation indicated that RIG-I specifically forms tetramers in complex with four unanchored poly-Ub; the $4: 4$ ratio remained constant with all $\mathrm{Ub}$ chain lengths tested, from $\mathrm{Ub}^{3}$ to $\mathrm{Ub}^{6}$. RIG-I formed high molecular weight complexes in response to viral infection in HEK-293T cells and MEFs, but not in Ubc13 knockout MEFs, or in RIG-I knockout MEFs expressing RIG-I that cannot bind Ub, leading the authors to conclude that RIG-I oligomerization depends on binding to Lys63-linked poly-Ub generated by Ubc13. When RIG-I was isolated from both types of knockout MEFs to use in in vitro IRF3 dimerization assays, only the higher molecular weight RIG-I aggregates were active, suggesting that Lys63-linked poly-Ubdependent oligomerization of RIG-I is necessary for its activity. Another RLR with a CARD domain, melanoma differentiationassociated protein 5 , behaves similarly to RIG-I in vitro, with Lys63-linked $\mathrm{Ub}^{6}$ inducing its oligomerization and enhancing its activation of IRF 3 in dimerization assays.

Hou et al. (2011) also used the cell-free RIG-I activation system to elucidate MAVS activation. Performing biochemical assays using isolated, crude mitochondrial extracts from virus-infected or uninfected HEK-293T cells, they determined that activated MAVS forms large, prion-like fibrils that induce
IRF3 dimerization. MAVS aggregation was induced by RIG-I in the presence of RNA and Lys63-linked, free $\mathrm{Ub}^{4}$. Based on these in vitro studies and the previous work from Zeng et al., the authors constructed a model for MAVS activation in the viral response that is dependent on binding of unanchored, Lys63linked poly-Ub to the CARD domains of RIG-I to trigger MAVS aggregation on the mitochondrial membrane (Figure 3; Hou et al., 2011). Crystal structure studies examining covalent and non-covalent binding between RIG-I and poly-Ub revealed that Lys63-linked free $\mathrm{Ub}^{2}$ binds RIG-I CARD tetramers, stabilizing them as a scaffold to recruit and activate MAVS to form fibrils in vitro (Peisley et al., 2014). Covalent poly-ubiquitination of RIG-I by TRIM25 also induced MAVS aggregation in vitro, indicating a potential for multiple Ub-dependent mechanisms to activate this important antiviral pathway. As mentioned above, TRIM25 is a Lys63-specific E3 that also produces at least some of the free poly-Ub chains that activate RIG-I in cultured human cells (Zeng et al., 2010). In vitro, the RING domain of TRIM25 partners with distinct E2s like Ubc13/Uev1a or Ubc5 to produce unanchored or substrate-conjugated Ub chains, respectively (Sanchez et al., 2016).

Another TRIM E3, TRIM6, is also involved in viral immunity through RIG-I signaling (Rajsbaum et al., 2014). As mentioned 
above, IFN IRF3's phosphorylation and activation are mediated by IKK $\varepsilon$ (Figure 3). Co-immunoprecipitation experiments using HEK-293T cells and primary human monocyte-derived dendritic cells showed an interaction between TRIM6 and IKKE, and knockdown of TRIM6 depleted IFN-mediated antiviral activity in human lung epithelial A549 cells (Rajsbaum et al., 2014). In vitro, IKK $\varepsilon$ interacted with free, Lys48-linked poly-Ub synthesized by TRIM6 and the E2, UBE2K, and USP5-sensitive poly-Ub interacted non-covalently with IKKع in HEK-293T cells, based on co-immunoprecipitation studies. By confocal microscopy, TRIM6 and IKKE co-localize with Ub-rich, cytoplasmic puncta in HeLa cells, and the formation of these puncta was disrupted by the introduction of USP5, which the authors interpreted to indicate the presence of free poly-Ub in the observed foci (Rajsbaum et al., 2014). In vitro phosphorylation assays revealed that untethered, Lys48-linked chains comprising 2 to $16 \mathrm{Ub}$ moieties induce IKK $\varepsilon$ autophosphorylation, causing IKK $\varepsilon$ oligomerization and IRF3 activation.

IKK $\varepsilon$ also contributes to the production of IFN-stimulated genes (ISGs) normally controlled by the JAK-STAT pathway. To activate this pathway, type I IFNs (IFN-I) bind heterodimeric interferon $-\alpha / \beta$ receptors (IFNARs) on the cell surface, and Janus kinase 1 (JAK1) and Tyrosine kinase 2 (TYK2) phosphorylate signal transducer and activator of transcription 1 (STAT1). Phosphorylated STAT1 forms the IFN-stimulated gene factor 3 (ISGF3) complex with STAT2 and IRF9, which translocates to the nucleus to induce transcription of ISGs (Hage and Rajsbaum, 2019). In vitro, IKK $\varepsilon$ activated by Lys48-linked unanchored polyUb directly phosphorylates STAT1 to promote ISGF3 complex formation and increase ISG production (Rajsbaum et al., 2014). Taken together, these studies (Zeng et al., 2010; Hou et al., 2011; Jiang et al., 2012; Rajsbaum et al., 2014; Hage and Rajsbaum, 2019) highlight the importance of two types of unanchored poly-Ub in innate immune pathways (Figure 3).

The participation of free poly-Ub in various immune responses is evidence that these chains have direct, physiological effects that are not limited to the proteasomal toxicity previously seen in yeast and in vitro systems (Figures 2, 3). As the pool of research on unanchored $\mathrm{Ub}$ chains has grown, there is increasing evidence that chain length and the type of linkage within the chain dictates its specific role in immune signaling [e.g., Lys63linked chains interact with RIG-I, while Lys48-linked chains activate IKK $\varepsilon$ (Zeng et al., 2010; Jiang et al., 2012; Rajsbaum et al., 2014)]. The roles of other linkage types remain to be studied in immune signaling and in other physiological processes; thus, it is quite possible that distinct species of free poly-Ub have yet-to-be discovered cellular functions.

\section{OTHER PHYSIOLOGICAL ROLES OF UNANCHORED UBIQUITIN CHAINS}

Other potential regulatory roles for free poly-Ub species have emerged, beyond their involvement in immune pathways. Braten et al. (2012) expressed a Ub $\Delta$ GG mutant in yeast and performed a gene deletion screen to determine which E2s and E3s are responsible for constructing $\mathrm{Ub} \Delta \mathrm{GG}$-terminal chains. By exposing these yeast strains to stressors, they observed that free Ub chains are upregulated during certain types of stress, including heat shock, DNA damage, and oxidative stress, and that the yeast E3, UFD4 generates unanchored chains under basal conditions, while another E3, HUL5 is responsible for most of the ones generated in response to a DNA alkylation agent (Braten et al., 2012). This study did not determine a physiological role for the free chains generated, but their stress-induced upregulation and the identification of two E3s responsible for them is notable and warrants further examination in this model organism and beyond.

Heat shock also induces the reversible formation of cytoplasmic stress granules, which are small, dense aggregations of proteins and mRNA. In cultured HeLa cells, USP5 is recruited to heat shock-induced stress granules, and its knockdown prevents their disassembly, leading Xie et al. (2018) to investigate the potential involvement of unanchored poly-Ub in this process. Heat shocking cells expressing Ub $\Delta$ GG led to the formation of stress granules at the same rate as cells expressing wild-type Ub, but more than twice as many $\mathrm{Ub} \Delta \mathrm{GG}$-expressing cells did not clear the newly formed granules (Xie et al., 2018). The authors concluded that untethered poly-Ub interferes with the process of disassembling stress granules; the specifics of this action remain to be determined.

Some cell stressors, including heat shock, can overwhelm or disrupt the proteasome, leading to a buildup of misfolded proteins in the cytosol. When the proteasome cannot meet demand, these proteins form Ub-rich aggregates, which are then amassed into larger inclusions called aggresomes. Aggresomes may be cytoprotective, as they prevent interactions with potentially toxic, misfolded proteins, and they can be eventually cleared via autophagy (Rodriguez-Gonzalez et al., 2008). Ouyang et al. (2012) linked aggresome formation to unanchored poly$\mathrm{Ub}$ associated with misfolded, aggregated proteins. In vitro binding assays revealed a direct interaction between the free C-termini of these $\mathrm{Ub}$ species and the ZnF-UBP domain of histone deacetylase 6 (HDAC6), which uses the dynein motor complex to transport aggregates to the microtubule organizing center, where aggresomes are formed (Ouyang et al., 2012). Interestingly, proteasomes associate with aggresomes, despite their inability to degrade misfolded protein aggregates within them (Wigley et al., 1999). Based on aggresome clearance assays and immunoprecipitation experiments in cultured HEK$293 \mathrm{~T}$ cells, unanchored Lys63-linked Ub chains created by en bloc cleavage by the proteasomal DUB, POH1 bind to and activate HDAC6, promoting clearance of aggresomes (Hao et al., 2013). In human lung carcinoma cells, the chaperone Hsp90 facilitates the remodeling of aggresome-associated proteasomes, freeing POH1 to efficiently release Lys63-linked unanchored Ub chains that activate HDAC6 and promote autophagic clearance (Nanduri et al., 2015).

Another fascinating aspect of free $\mathrm{Ub}$ chains is their counterintuitive contribution to the survival and propagation of viruses within a host organism. Viruses often inhibit immune signaling or exploit normal cellular processes to increase infection, sometimes by directly manipulating unanchored polyUb signaling (Hage and Rajsbaum, 2019). Nipah virus, a zoonotic virus that can be fatal in humans, has a matrix protein that antagonizes the RIG-I and IFN-I immune pathways by inhibiting 
the E3 ligase TRIM6's production of Lys48-linked unanchored chains; consequently, IKKE is not activated to phosphorylate IRF3 and STAT1, reducing IFN and ISG production (Bharaj et al., 2016). Influenza A viruses (IAVs) use untethered poly$\mathrm{Ub}$ to promote viral uncoating: mimicking misfolded protein aggregates, IAV capsids containing free poly-Ub species recruit HDAC6. Together with cytoskeletal motor proteins, HDAC6 processes the capsid as an aggresome, disassembling it and releasing the viral DNA (Banerjee et al., 2014).

Thus far, not many physiological functions have been ascribed to unanchored poly-Ub; but, it is important to note that they indeed have innate roles and do not appear to simply be byproducts of chain assembly and disassembly. Clearly, additional investigations are needed in intact organisms and in specific cell types and tissues to explore and understand their physiological implications. In the next section, we further explore the idea of free Ub chain toxicity and utilization by discussing outcomes from studies in an intact, multicellular organism, the fruit fly.

\section{REDUCED OR ABSENT TOXICITY FROM UNANCHORED POLY-UBIQUITIN IN Drosophila melanogaster}

The involvement of free poly-Ub in several cellular pathways casts them in a new, more complex light. Given that several types of unanchored chains are now well-characterized as second messengers in immune pathways, it is important to understand their regulation. How do cells maintain optimal levels of the specific types of free poly-Ub they need? When free poly-Ub levels are elevated in an intact organism, is there associated proteasomal inhibition, and furthermore, is that inhibition toxic? What additional signaling roles might there be for untethered Ub chains? In an effort to better understand the physiological functions, regulation, and potential toxicity of unanchored chains, our laboratory conducted a series of studies to determine their impact in an intact, multi-cellular organism. Our collective results provide additional nuance to the emerging understanding of the diversity of unanchored poly-Ub species and their narrow potential for toxicity.

We began our investigations by designing two types of unanchored poly-Ub transgenes to express in D. melanogaster. Both types of chains consist of six Ub in tandem and lack internal "GG" motifs that are necessary for isopeptide bond formation and disassembly (Komander et al., 2009; Komander and Rape, 2012; Blount et al., 2018; Clague et al., 2019). Whereas one type of chain also lacks a terminal "GG," and thus cannot be conjugated onto other proteins (referred to as $\mathrm{Ub}^{6}$-Stop), the other chain type contains a "GG" motif at its end to allow for protein conjugation (referred to as $\mathrm{Ub}^{6}-\mathrm{GG}$; Figure 4). Their expression was enabled by the binary, Gal4-UAS system, which allows for tissue-specific as well as timed expression through specific "drivers" and compounds delivered in fly media (Brand and Perrimon, 1993; Brand et al., 1994; Osterwalder et al., 2001; Roman et al., 2001).
Biochemical analyses of the Drosophila lines generated with these transgenic free $\mathrm{Ub}$ chains showed robust expression and ample modification by endogenous Ub, effectively creating branched Ub chains with various linkage combinations (Blount et al., 2018). When expressed in all cells, $\mathrm{Ub}^{6}$ did not impact Drosophila development or adult fly longevity under both normal and heat-stressed conditions. Specific expression in several tissues had moderate effects on longevity, with glial and neuronal expression reducing fly lifespan by a few days (Blount et al., 2018). Overall, longevity results indicated that unanchored chains are not necessarily toxic.

Because of studies indicating an inhibitory role for unanchored poly-Ub at the proteasome in vitro and in yeast, proteasomal activity was assessed in flies expressing, or not, $\mathrm{Ub}^{6}$-Stop in all cells. Expression of $\mathrm{Ub}^{6}$-Stop (which cannot itself be conjugated onto other proteins and thus remains unanchored) did not affect protein levels of proteasomal components, nor did it hinder the turnover of known proteasomal substrates (Blount et al., 2018), suggesting that these linear Ub species do not affect proteasomal function in the manners observed with certain free chains in vitro and in yeast. Genetic and biochemical studies indicated that $\mathrm{Ub}^{6}$-Stop is itself degraded by the proteasome, highlighting this mechanism as a key regulator of the stability of linear, unanchored poly-Ub in the fly.

Generally, ubiquitination is considered to occur via serial addition of mono-Ub onto an extending chain or substrate. Intriguingly, the conjugation-capable $\mathrm{Ub}^{6}$-GG could be attached as a single unit onto other proteins in flies and in cultured, HEK293 mammalian cells (Blount et al., 2018). These results suggest that $\mathrm{Ub}$ recycling need not only occur at the level of a monomer; in fact, a whole chain might be removed from one substrate and attached onto another en bloc. While the notion of en bloc transfer of an intact chain, without its disassembly into mono-Ub, has been purported before and has been observed in vitro (Bamezai et al., 1989; Chen and Pickart, 1990; Li et al., 2007; Masuda et al., 2012), insofar as we know it had not been shown before in a cell or intact animal. These findings led to the possibility of free poly-Ub regulation beyond their disassembly into mono-Ub: they can be degraded by the proteasome, or become conjugated onto other proteins whole-sale, painting a wider tableau of possibilities for unanchored chain regulation in the cell.

Because of the surprising finding that untethered, linear polyUb species are not toxic in flies (Blount et al., 2018), we wondered whether Drosophilae mount a response toward these chains. We examined changes at the transcriptional level through RNAseq, using flies expressing everywhere $\mathrm{Ub}^{6}$-Stop, $\mathrm{Ub}^{6}-\mathrm{GG}$, or no transgene with the same genetic background. The presence of each type of $\mathrm{Ub}^{6}$ chain led to significant changes in the expression of approximately 90 fly genes, but with no clear, coordinated cellular response to indicate the induction of any particular pathways (Blount et al., 2019). Only 30\% of the altered Drosophila transcripts observed have assigned gene names, and $27 \%$ of the genes had no predicted function, opening up the potential for the future identification and characterization of proteins that interact with untethered poly-Ub. It appears that the expression of unanchored poly-Ub in Drosophila translates to minimal transcriptomic or organismal response, judging by 


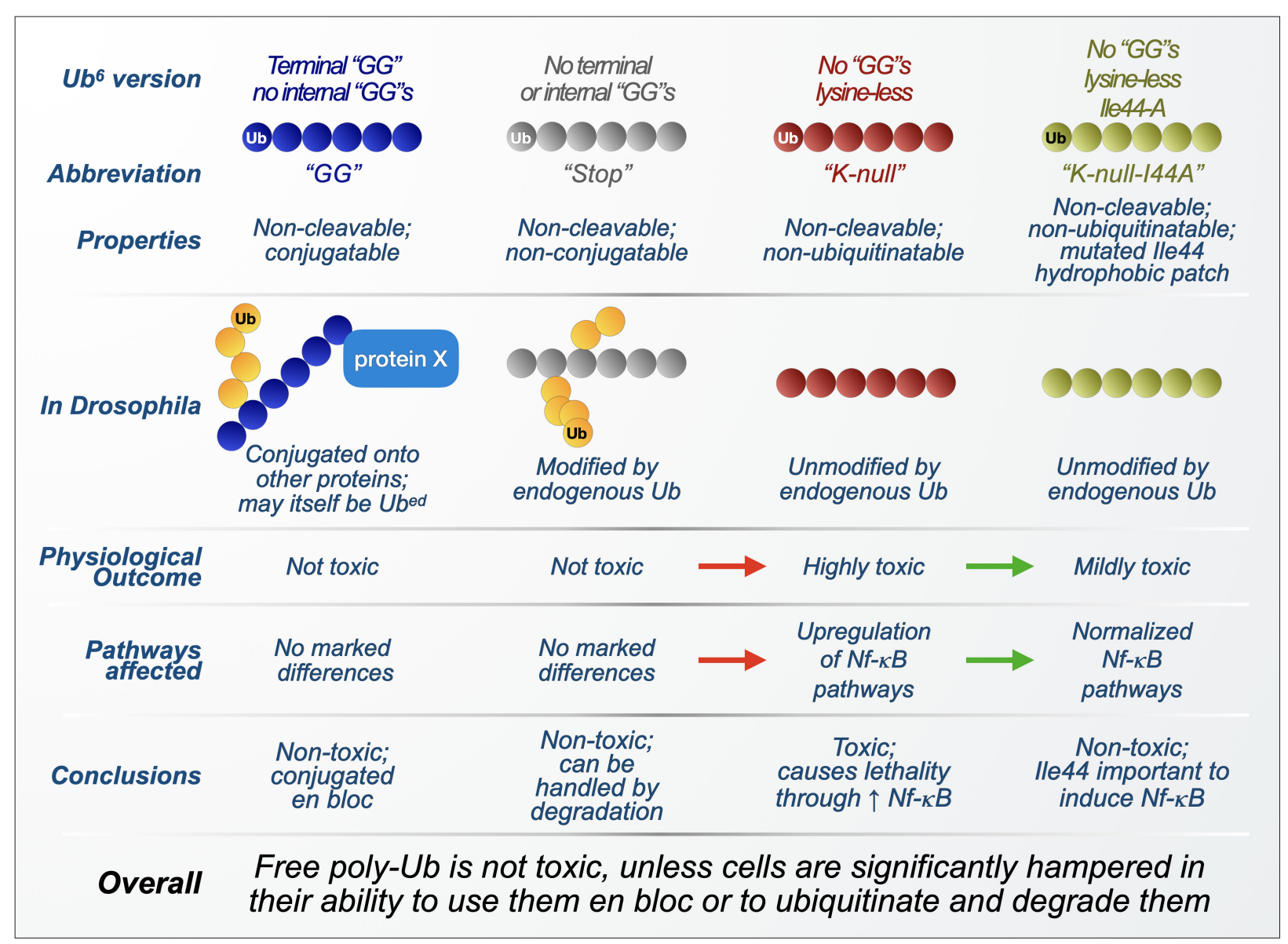

FIGURE 4 | Summary of findings from transgenic, unanchored poly-ubiquitin in Drosophila. Overview of the composition, processing, and physiological effects of unanchored ubiquitin chains used in Drosophila melanogaster. Red arrows: worsening of phenotypes and outcomes as free poly-ubiquitin is mutated to become resistant to its own ubiquitination. Green arrows: improvement of phenotypes and outcomes as ubiquitination-resistant, free poly-ubiquitin is further modified to inactivate its lle44 hydrophobic patch. Yellow circles: endogenous ubiquitin proteins.

the low number of altered transcripts and a lack of specificity for Ub-related pathways in those transcripts that were altered (Blount et al., 2019).

The lack of notable toxicity from linear hexa-Ub chains in Drosophila does not dovetail with earlier studies that strongly indicated that unanchored chains toxically inhibit the proteasome in yeast (Hadari et al., 1992; Amerik et al., 1997; Piotrowski et al., 1997; Thrower et al., 2000), leading us to wonder how unique characteristics of unanchored poly- $\mathrm{Ub}$ species control their effects. As previously mentioned, $\mathrm{Ub}^{6}$ Stop is ubiquitinated in flies, introducing endogenous $\mathrm{Ub}$ that could potentially change the way these chains are handled (Blount et al., 2018). To assess the influence of endogenous ubiquitination on the toxicity of unanchored chains, we mutated all lysine residues in $\mathrm{Ub}^{6}$-Stop to alanine, creating $\mathrm{Ub}^{6}$-StopK0, a ubiquitination-resistant, linear hexa-Ub chain that cannot be cleaved by DUBs or conjugated onto a substrate (Figure 4). Mirroring the longevity assays we used to characterize $\mathrm{Ub}^{6}$, we observed that $\mathrm{Ub}^{6}$-Stop-K0 is significantly more toxic than its ubiquitination-prone counterpart: its expression markedly reduces fly lifespan or is developmentally lethal, depending on expression pattern (Blount et al., 2020). Compared to the ubiquitination-prone $\mathrm{Ub}^{6}$, turnover of $\mathrm{Ub}^{6}$-Stop-K0 is slowed but not halted, indicating that ubiquitination aids in the turnover of linear $\mathrm{Ub}^{6}$, but is not essential to its eventual clearance (Blount et al., 2020).

To explain the enhanced toxicity of ubiquitination-resistant $\mathrm{Ub}^{6}$, we turned to the previously described studies linking unanchored poly-Ub to NF-кB pathways (Xia et al., 2009; Rahighi et al., 2009; Zeng et al., 2010; Hou et al., 2011; Skaug et al., 2011; Jiang et al., 2012; Rajsbaum et al., 2014; Catici et al., 2015), reasoning that $\mathrm{Ub}^{6}$-Stop-K0 could increase NF- $\mathrm{kB}$ signaling (Zhou et al., 2005; Valanne et al., 2011; Chen and Chen, 2013; Myllymaki et al., 2014; Courtois and Fauvarque, 2018). In RNAi studies, knockdown of NF- $\kappa \mathrm{B}$ components extends the lifespan of $\mathrm{Ub}^{6}$-Stop-K0 flies, although not to the extent of controls (Blount et al., 2020). RT-qPCR revealed that $\mathrm{Ub}^{6}$-Stop-K0 expression causes an increase in mRNA levels of several of these NF- $\mathrm{kB}$ components (Blount et al., 2020). Based on these results, we concluded that ubiquitination-resistant, linear Ub chains induce aberrant NF- $\kappa \mathrm{B}$ signaling, accounting for at least some of its toxicity in flies. 
The studies described in section "Unanchored Chains and Their Physiological Roles in Immunity" show direct interaction between unanchored Ub chains and several Ub-binding proteins that specifically recognize Ub's Ile44-centered hydrophobic patch, including TAB2 and NEMO (Beal et al., 1996, 1998; SloperMould et al., 2001; Dikic et al., 2009; Komander and Rape, 2012). We thus examined the hydrophobic patch's role in NF- $\kappa$ Bmediated toxicity from $\mathrm{Ub}^{6}$-Stop-K0, mutating Ile44 to alanine in each $\mathrm{Ub}$ moiety to create the binding-deficient mutant $\mathrm{Ub}^{6}$ Stop-K0-Ile44a (Figure 4). These mutations reversed most of the toxicity as well as aberrant NF- $\mathrm{B}$ signaling in flies and also in cultured, HEK-293T cells (Blount et al., 2020). These results indicated a role for free, linear, ubiquitination-resistant chains in NF- $\kappa$ B signaling that depends on an intact Ile44 hydrophobic patch; without Ile44, ubiquitination-resistant $\mathrm{Ub}^{6}$ likely is unable to interact with Ub-binding NF- $\mathrm{B}$ components, prohibiting much of its toxicity in vivo.

Taken together, these studies (Blount et al., 2018, 2019, 2020) add yet more complexity to the general understanding of unanchored poly-Ub. Clearly, free Ub chains are not always toxic. In flies, linear hexa-Ub chains are well tolerated, as long as they can be ubiquitinated or conjugated onto other proteins. Due to the current unavailability of genetic techniques to stably express in the fly chains of different topologies and linkages, we were restricted to using linear, head-to-tail chains. However, it bears highlighting that these linear chains are quickly and abundantly decorated with endogenous Ub, and are thus transformed into a pool of free $\mathrm{Ub}$ species that comprises linear as well as branched chains consisting of M1, K27, K48, and K63 linkages (Blount et al., 2018). Consequently, the findings summarized in this section pertain to various types of free poly-Ub in vivo and, with the above caveats in mind, may be extrapolated to apply more widely to other types of chains. Additionally, the fact that all of these $\mathrm{Ub}^{6}$ mutants are based on the same backbone - Met1linked hexa-Ub - but behave differently in Drosophila is evidence of the complicated nature of unanchored poly-Ub in vivo.

\section{PERSPECTIVES}

The studies described in this review provide a complex picture of unanchored poly-Ub handling and function. It is now apparent that the previous understanding of these chains - that they only exist briefly before being disassembled by DUBs to prevent toxicity and allow mono-Ub recycling - is only part of the

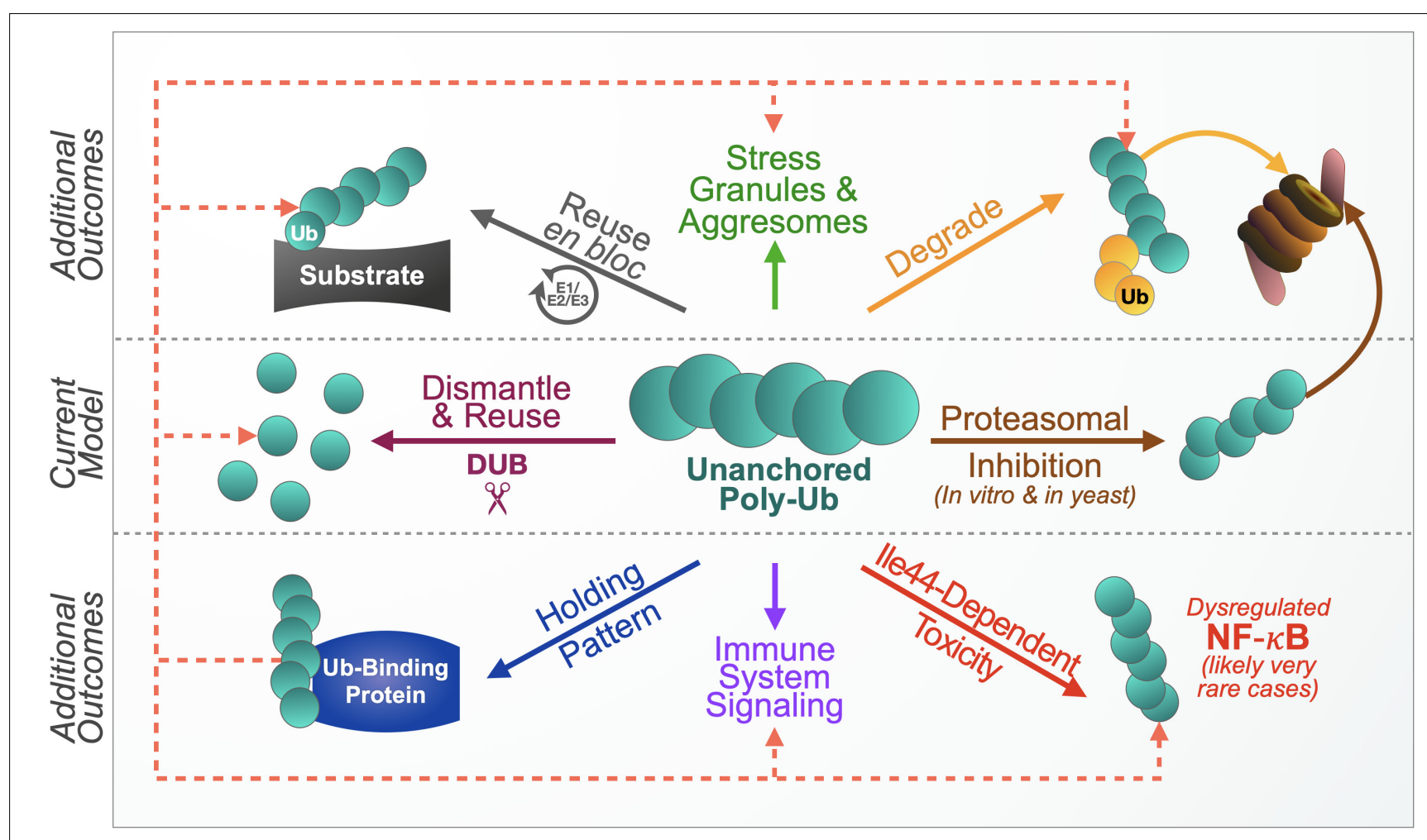

FIGURE 5 | Proposed model of unanchored ubiquitin chain use and control. The current model presents one primary mechanism of handling free chains, their disassembly. Based on increasing evidence, we propose additional outcomes. Free chains can be degraded by the proteasome without inhibiting it, either as they are, or with additional ubiquitination by endogenous ubiquitin (yellow circles). Another mechanism may be achieved through en bloc conjugation onto other substrates. Unanchored ubiquitin chains may also associate with ubiquitin-binding proteins in a "reserve" pool for later use in any of the other suggested routes of management (dotted lines). Untethered poly-ubiquitin species also participate in normal immune signaling and response to cellular stress. Lack of control of free chains could lead to adverse outcomes, such as when unanchored poly-ubiquitin that cannot themselves become ubiquitinated activate NF- $\mathrm{B}$ signaling. These possibilities are probably fluidly connected to enable free chain designation among different roles and regulatory routes. We did not depict these intersections in an effort of simplifying the diagram. Additional regulatory mechanisms and functions likely exist. 
picture. These members of the Ub family have clear physiological roles and seem to be controlled in ways that have not garnered much attention so far. It appears that untethered Ub chains are regulated through various mechanisms. Not all of the possibilities we present next need to exist and operate at the same time in each cell. They may be cell type- and cell condition-dependent. Also, evolutionary differences may place more weight on some such pathways compared to others.

We propose the following routes of unanchored poly-Ub control and recycling (Figure 5). The first and in all likelihood major route of regulation and recycling remains the disassembly of free chains into mono-Ub so that they can be reused to modify other proteins. A second route may be that of unanchored poly-Ub degradation, either as they are or through additional decoration by endogenous Ub. A third mechanism of free poly-Ub use and control may be their en bloc conjugation onto another substrate, essentially removing them from the unanchored population. Additionally, free chains may associate with Ub-binding proteins in a type of "reserve" pool until they can be re-utilized, which may function in conjunction with the other proposed routes of unanchored chain management. In an example of the latter route - and under special conditions where they may not be able to be dispensed of or controlled in other ways - free Ub chains can interact with NF-кB signaling components, causing abnormal signaling and toxicity. Free poly$\mathrm{Ub}$ is clearly involved in normal immune signaling, and also appears to be involved with stress granule clearance. What we present is not an exhaustive tableau of potential outcomes; further studies will likely lead to the discovery of additional functions and cellular responses.

It may seem that more recent studies revealing unanchored Ub's physiological roles and lack of toxicity contradict earlier studies that characterized free poly-Ub as harmful, but the seeming discordance only highlights the importance of Ub chain type and context. Some of the previous in vitro and yeast studies that suggested proteasomal inhibition by untethered polyUb focused on Lys48-linked chains (Piotrowski et al., 1997; Thrower et al., 2000; Dayal et al., 2009), while the $\mathrm{Ub}^{6}$ chains expressed in Drosophila are head-to-tail (Blount et al., 2018, 2019). In principle, it makes sense that unanchored chains that resemble poly-Ub attached to proteasome-targeted proteins which are often Lys48-linked - could outcompete proteasomal substrates in a manner not observed with linear chains that are not traditionally associated with proteasomal degradation (Piotrowski et al., 1997; Thrower et al., 2000; Komander and Rape, 2012). This out-competition most likely depends on chain abundance compared to endogenous substrates. [We should note here that in the fly linear chains that could become ubiquitinated, including with Lys48 linkages, did not impact proteasome activity and both ubiquitination-capable and -resistant free $\mathrm{Ub}^{6}$ were turned over in the fly, with the latter being a little delayed in the earlier stages of its degradation (Blount et al., 2018, 2020).] Proximity to the proteasome is likely key: in vitro proteasome assays allow close association between $\mathrm{Ub}$ chains and the proteasome, with few proteins present to interfere, while $\mathrm{Ub}^{6}$ expression in transgenic flies does not guarantee such proximity. It is also clear that free poly-Ub toxicity is dependent on post-translational modification of the chain and its interactions with other proteins. Linear $\mathrm{Ub}^{6}$ species did not become particularly toxic until they could no longer be used or modified, at which point they were highly toxic in a manner dependent on their ability to interact with other proteins' Ubbinding domains. Future studies need to take into account post-translational modifications and interactions that affect free poly-Ub function and processing.

It also stands to reason that there could be evolutionary differences between single-cell organisms like yeast, in which free poly-Ub is toxic, and higher order organisms that may have evolved compensatory mechanisms or pathways that utilize these chains. One function for untethered $\mathrm{Ub}$ chains that may be conserved between yeast and mammals involves stress granules: in cultured HeLa cells, free poly-Ub interferes with the clearance of stress granules (Xie et al., 2018). Yeast also form stress granules (Wheeler et al., 2017), and they produce free poly-Ub species in response to stressors like heat shock and DNA alkylation (Braten et al., 2012), but an interplay between stress granules and unanchored Ub chains has not been reported in yeast. In contrast to the conservation of stress granules, we described several studies linking unanchored Ub chains to signaling pathways that are not present in yeast (Srinivasan et al., 2010). Unanchored Ub chains can both positively and negatively regulate NF- $\kappa \mathrm{B}$ pathways and viral response in multi-cellular organisms (Xia et al., 2009; Zeng et al., 2010; Hou et al., 2011; Skaug et al., 2011; Jiang et al., 2012; Emmerich et al., 2013; Peisley et al., 2014; Rajsbaum et al., 2014; Catici et al., 2015), but yeast do not have bona fide NF-кB pathways. Continued studies will be essential to the discovery of additional physiological functions for free poly-Ub that may not be present in single-cell organisms.

\section{CONCLUSIONS AND FUTURE DIRECTIONS}

Exciting research opportunities await unanchored $\mathrm{Ub}$ chain biology. Different species of free poly-Ub have unique effects; it will be important to distinguish the type of chain responsible for specific actions within cells, and under what circumstances these actions take place. Markers that recognize unanchored poly-Ub with specific linkage types could be developed to aid in the identification of chain types that are upregulated during certain stress responses, or in the mapping of the cellular distribution of different, untethered poly-Ub species. Since poly-Ub can be transferred en bloc to substrates in vivo, it will be interesting to investigate whether there are situations in which cells may prefer to use pre-formed chains for ubiquitination - e.g., perhaps the increased demand to replenish ATP during exercise (Baker et al., 2010) promotes the use of pre-formed chains as an ATP-preserving method of poly-ubiquitination. Proteomic-based studies alongside genetic and biochemical investigations will be needed to identify E2s and E3s that can transfer Ub chains en bloc, and they can provide additional clues about pathways that involve free chains by identifying signaling proteins that bind or interact with them.

The collection of studies summarized here highlights that unanchored poly-Ub species are multi-faceted entities. These prior investigations necessitate further examinations to 
comprehensively understand the consequences of their presence in the cell and, by extension, to better understand the intricacies of Ub biology and its roles in normal physiology and in disease.

\section{AUTHOR CONTRIBUTIONS}

JB, SJ, and ST wrote and edited the manuscript. All authors approved the submitted version.

\section{REFERENCES}

Abdul Rehman, S. A., Kristariyanto, Y. A., Choi, S. Y., Nkosi, J., Weidlich, S., Labib, K., et al. (2016). MINDY-1 Is a member of an evolutionarily conserved and structurally distinct new family of deubiquitinating enzymes. Mol. Cell. 63, 146-155. doi: 10.1016/j.molcel.2016.05.009

Al-Hakim, A., Escribano-Diaz, C., Landry, M. C., O’Donnell, L., Panier, S., Szilard, R. K., et al. (2010). The ubiquitous role of ubiquitin in the DNA damage response. DNA Repair (Amst) 9, 1229-1240. doi: 10.1016/j.dnarep.2010.09.011

Al-Hakim, A. K., Zagorska, A., Chapman, L., Deak, M., Peggie, M., and Alessi, D. R. (2008). Control of AMPK-related kinases by USP9X and atypical Lys(29)/Lys(33)-linked polyubiquitin chains. Biochem. J. 411, 249-260. doi: $10.1042 /$ bj20080067

Alpi, A. F., Pace, P. E., Babu, M. M., and Patel, K. J. (2008). Mechanistic insight into site-restricted monoubiquitination of FANCD2 by Ube2t. FANCL, and FANCI. Mol. Cell 32, 767-777. doi: 10.1016/j.molcel.2008.12.003

Amerik, A., Swaminathan, S., Krantz, B. A., Wilkinson, K. D., and Hochstrasser, M. (1997). In vivo disassembly of free polyubiquitin chains by yeast Ubp14 modulates rates of protein degradation by the proteasome. Embo J. 16, 48264838. doi: $10.1093 / \mathrm{emboj} / 16.16 .4826$

Baboshina, O. V., and Haas, A. L. (1996). Novel multiubiquitin chain linkages catalyzed by the conjugating enzymes E2EPF and RAD6 are recognized by 26 S proteasome subunit 5. J. Biol. Chem. 271, 2823-2831. doi: 10.1074/jbc.271.5. 2823

Baker, J. S., McCormick, M. C., and Robergs, R. A. (2010). Interaction among skeletal muscle metabolic energy systems during intense exercise. J. Nutr. Metab. 2010:905612.

Bamezai, S., Tate, S., and Breslow, E. (1989). Inhibition of ubiquitin-dependent proteolysis by des-Gly-Gly-ubiquitin: implications for the mechanism of polyubiquitin synthesis. Biochem. Biophys. Res. Commun. 162, 89-94. doi: 10.1016/0006-291x(89)91966-9

Banerjee, I., Miyake, Y., Nobs, S. P., Schneider, C., Horvath, P., Kopf, M., et al. (2014). Influenza A virus uses the aggresome processing machinery for host cell entry. Science 346, 473-477. doi: 10.1126/science. 1257037

Beal, R., Deveraux, Q., Xia, G., Rechsteiner, M., and Pickart, C. (1996). Surface hydrophobic residues of multiubiquitin chains essential for proteolytic targeting. Proc. Natl. Acad. Sci. U.S.A. 93, 861-866. doi: 10.1073/pnas.93.2.861

Beal, R. E., Toscano-Cantaffa, D., Young, P., Rechsteiner, M., and Pickart, C. M. (1998). The hydrophobic effect contributes to polyubiquitin chain recognition. Biochemistry 37, 2925-2934. doi: 10.1021/bi972514p

Bellare, P., Small, E. C., Huang, X., Wohlschlegel, J. A., Staley, J. P., and Sontheimer, E. J. (2008). A role for ubiquitin in the spliceosome assembly pathway. Nat. Struct. Mol. Biol. 15, 444-451. doi: 10.1038/nsmb.1401

Bentley, M. L., Corn, J. E., Dong, K. C., Phung, Q., Cheung, T. K., and Cochran, A. G. (2011). Recognition of $\mathrm{UbcH} 5 \mathrm{c}$ and the nucleosome by the Bmil/Ringlb ubiquitin ligase complex. EMBO J. 30, 3285-3297. doi: 10.1038/emboj.2011.243

Besche, H. C., Sha, Z., Kukushkin, N. V., Peth, A., Hock, E. M., Kim, W., et al. (2014). Autoubiquitination of the $26 \mathrm{~S}$ proteasome on Rpn13 regulates breakdown of ubiquitin conjugates. EMBO J. 33, 1159-1176. doi: 10.1002/embj. 201386906

Bharaj, P., Wang, Y. E., Dawes, B. E., Yun, T. E., Park, A., Yen, B., et al. (2016). The matrix protein of nipah virus targets the E3-ubiquitin Ligase TRIM6 to inhibit the IKKepsilon kinase-mediated Type-I IFN antiviral response. PLoS Pathog 12:e1005880. doi: 10.1371/journal.ppat.1005880

\section{FUNDING}

This work was funded by a Thomas Rumble Graduate Fellowship to JB from Wayne State University Graduate School, by a Competitive Graduate Research Assistantship to JB from Wayne State University Graduate School, by a Competitive Graduate Research Assistantship to SJ from Wayne State University Graduate School, and by R01NS086778 to ST from the National Institute of Neurological Disorders and Stroke.

Bienko, M., Green, C. M., Crosetto, N., Rudolf, F., Zapart, G., Coull, B., et al. (2005). Ubiquitin-binding domains in Y-family polymerases regulate translesion synthesis. Science 310, 1821-1824. doi: 10.1126/science.1120615

Bienko, M., Green, C. M., Sabbioneda, S., Crosetto, N., Matic, I., Hibbert, R. G., et al. (2010). Regulation of translesion synthesis DNA polymerase eta by monoubiquitination. Mol. Cell 37, 396-407.

Bingol, B., Tea, J. S., Phu, L., Reichelt, M., Bakalarski, C. E., Song, Q., et al. (2014). The mitochondrial deubiquitinase USP30 opposes parkin-mediated mitophagy. Nature 510, 370-375. doi: 10.1038/nature13418

Blount, J. R., Libohova, K., Marsh, G. B., Sutton, J. R., and Todi, S. V. (2018). Expression and regulation of deubiquitinase-resistant, unanchored ubiquitin chains in Drosophila. Sci. Rep. 8:8513.

Blount, J. R., Libohova, K., Silva, G. M., and Todi, S. V. (2020). Isoleucine 44 hydrophobic patch controls toxicity of unanchored, linear ubiquitin chains through NF-кB signaling. Cells 9:1519. doi: 10.3390/cells9061519

Blount, J. R., Meyer, D. N., Akemann, C., Johnson, S. L., Gurdziel, K., Baker, T. R., et al. (2019). Unanchored ubiquitin chains do not lead to marked alterations in gene expression in Drosophila melanogaster. Biol. Open 8:bio043372. doi: 10.1242/bio.043372

Bosanac, I., Phu, L., Pan, B., Zilberleyb, I., Maurer, B., Dixit, V. M., et al. (2011). Modulation of K11-linkage formation by variable loop residues within UbcH5A. J. Mol. Biol. 408, 420-431. doi: 10.1016/j.jmb.2011.03.011

Brand, A. H., Manoukian, A. S., and Perrimon, N. (1994). Ectopic expression in Drosophila. Methods Cell Biol. 44, 635-654.

Brand, A. H., and Perrimon, N. (1993). Targeted gene expression as a means of altering cell fates and generating dominant phenotypes. Development 118, 401-415.

Braten, O., Shabek, N., Kravtsova-Ivantsiv, Y., and Ciechanover, A. (2012). Generation of free ubiquitin chains is up-regulated in stress and facilitated by the HECT domain ubiquitin ligases UFD4 and HUL5. Biochem. J. 444, 611-617. doi: 10.1042/bj20111840

Bremm, A., Freund, S. M., and Komander, D. (2010). Lys11-linked ubiquitin chains adopt compact conformations and are preferentially hydrolyzed by the deubiquitinase Cezanne. Nat. Struct. Mol. Biol. 17, 939-947. doi: 10.1038/nsmb. 1873

Bremm, A., and Komander, D. (2011). Emerging roles for Lys11-linked polyubiquitin in cellular regulation. Trends Biochem. Sci. 36, 355-363.

Bremm, A., Moniz, S., Mader, J., Rocha, S., and Komander, D. (2014). Cezanne (OTUD7B) regulates HIF-1 $\alpha$ homeostasis in a proteasome-independent manner. EMBO Rep. 15, 1268-1277. doi: 10.15252/embr.201438850

Cao, Z., Xiong, J., Takeuchi, M., Kurama, T., and Goeddel, D. V. (1996). TRAF6 is a signal transducer for interleukin-1. Nature 383, 443-446. doi: 10.1038/ $383443 \mathrm{a} 0$

Castańeda, C. A., Kashyap, T. R., Nakasone, M. A., Krueger, S., and Fushman, D. (2013). Unique structural, dynamical, and functional properties of k11-linked polyubiquitin chains. Structure 21, 1168-1181. doi: 10.1016/j.str.2013.04.029

Catici, D. A., Horne, J. E., Cooper, G. E., and Pudney, C. R. (2015). Polyubiquitin Drives the Molecular Interactions of the NF-kappaB Essential Modulator (NEMO) by Allosteric Regulation. J. Biol. Chem. 290, 14130-14139. doi: 10. 1074/jbc.m115.640417

Chau, V., Tobias, J. W., Bachmair, A., Marriott, D., Ecker, D. J., Gonda, D. K., et al. (1989). A multiubiquitin chain is confined to specific lysine in a targeted short-lived protein. Science 243, 1576-1583. doi: 10.1126/science.253 8923 
Chen, B., Mariano, J., Tsai, Y. C., Chan, A. H., Cohen, M., and Weissman, A. M. (2006). The activity of a human endoplasmic reticulum-associated degradation E3, gp78, requires its Cue domain, RING finger, and an E2binding site. Proc. Natl. Acad. Sci. U.S.A. 103, 341-346. doi: 10.1073/pnas.05066 18103

Chen, J., and Chen, Z. J. (2013). Regulation of NF-kappaB by ubiquitination. Curr. Opin. Immunol. 25, 4-12.

Chen, R. H., Chen, Y. H., and Huang, T. Y. (2019). Ubiquitin-mediated regulation of autophagy. J. Biomed. Sci. 26:80.

Chen, Z., and Pickart, C. M. (1990). A 25-kilodalton ubiquitin carrier protein (E2) catalyzes multi-ubiquitin chain synthesis via lysine 48 of ubiquitin. J. Biol. Chem. 265, 21835-21842.

Chen, Z. J., and Sun, L. J. (2009). Nonproteolytic functions of ubiquitin in cell signaling. Mol. Cell 33, 275-286. doi: 10.1016/j.molcel.2009.01.014

Chew, K. C., Matsuda, N., Saisho, K., Lim, G. G., Chai, C., Tan, H. M., et al. (2011). Parkin mediates apparent E2-independent monoubiquitination in vitro and contains an intrinsic activity that catalyzes polyubiquitination. PLoS One 6:e19720. doi: 10.1371/journal.pone.0019720

Christensen, D. E., Brzovic, P. S., and Klevit, R. E. (2007). E2-BRCA1 RING interactions dictate synthesis of mono- or specific polyubiquitin chain linkages. Nat. Struct. Mol. Biol. 14, 941-948. doi: 10.1038/nsmb1295

Christensen, D. E., and Klevit, R. E. (2009). Dynamic interactions of proteins in complex networks: identifying the complete set of interacting E2s for functional investigation of E3-dependent protein ubiquitination. FEBS J. 276, 5381-5389. doi: $10.1111 / \mathrm{j} .1742-4658.2009 .07249 . \mathrm{x}$

Clague, M. J., Barsukov, I., Coulson, J. M., Liu, H., Rigden, D. J., and Urbe, S. (2013). Deubiquitylases from genes to organism. Physiol. Rev. 93, 1289-1315. doi: 10.1152/physrev.00002.2013

Clague, M. J., Coulson, J. M., and Urbe, S. (2012). Cellular functions of the DUBs. J. Cell Sci. 125(Pt 2), 277-286. doi: 10.1242/jcs.090985

Clague, M. J., Urbe, S., and Komander, D. (2019). Breaking the chains: deubiquitylating enzyme specificity begets function. Nat. Rev. Mol. Cell Biol. 20, 338-352. doi: 10.1038/s41580-019-0099-1

Courtois, G., and Fauvarque, M. O. (2018). The many roles of ubiquitin in NF-kappaB signaling. Biomedicines 6:43. doi: 10.3390/biomedicines6020043

Cunningham, C. N., Baughman, J. M., Phu, L., Tea, J. S., Yu, C., Coons, M., et al. (2015). USP30 and parkin homeostatically regulate atypical ubiquitin chains on mitochondria. Nat. Cell Biol. 17, 160-169. doi: 10.1038/ncb3097

Damgaard, R. B., Nachbur, U., Yabal, M., Wong, W. W., Fiil, B. K., Kastirr, M., et al. (2012). The ubiquitin ligase XIAP recruits LUBAC for NOD2 signaling in inflammation and innate immunity. Mol. Cell 46, 746-758. doi: 10.1016/j. molcel.2012.04.014

Dammer, E. B., Na, C. H., Xu, P., Seyfried, N. T., Duong, D. M., Cheng, D., et al. (2011). Polyubiquitin linkage profiles in three models of proteolytic stress suggest the etiology of Alzheimer disease. J. Biol. Chem. 286, 10457-10465. doi: 10.1074/jbc.m110.149633

Dayal, S., Sparks, A., Jacob, J., Allende-Vega, N., Lane, D. P., and Saville, M. K. (2009). Suppression of the deubiquitinating enzyme USP5 causes the accumulation of unanchored polyubiquitin and the activation of p53. J. Biol. Chem. 284, 5030-5041. doi: 10.1074/jbc.m805871200

Deng, L., Wang, C., Spencer, E., Yang, L., Braun, A., You, J., et al. (2000). Activation of the IkappaB kinase complex by TRAF6 requires a dimeric ubiquitinconjugating enzyme complex and a unique polyubiquitin chain. Cell 103, 351-361. doi: 10.1016/s0092-8674(00)00126-4

Deveraux, Q., Ustrell, V., Pickart, C., and Rechsteiner, M. (1994). A 26 S protease subunit that binds ubiquitin conjugates. J. Biol. Chem. 269, 7059-7061.

Dikic, I., Wakatsuki, S., and Walters, K. J. (2009). Ubiquitin-binding domains - from structures to functions. Nat. Rev. Mol. Cell Biol. 10, 659-671. doi: $10.1038 / \mathrm{nrm} 2767$

Doil, C., Mailand, N., Bekker-Jensen, S., Menard, P., Larsen, D. H., Pepperkok, R., et al. (2009). RNF168 binds and amplifies ubiquitin conjugates on damaged chromosomes to allow accumulation of repair proteins. Cell 136, 435-446. doi: 10.1016/j.cell.2008.12.041

Doss-Pepe, E. W., Chen, L., and Madura, K. (2005). Alpha-synuclein and parkin contribute to the assembly of ubiquitin lysine 63-linked multiubiquitin chains. J. Biol. Chem. 280, 16619-16624. doi: 10.1074/jbc.m413591200

Dupont, S., Mamidi, A., Cordenonsi, M., Montagner, M., Zacchigna, L., Adorno, M., et al. (2009). FAM/USP9x, a deubiquitinating enzyme essential for TGFbeta signaling, controls Smad4 monoubiquitination. Cell 136, 123-135. doi: 10 . 1016/j.cell.2008.10.051

Durcan, T. M., Tang, M. Y., Pérusse, J. R., Dashti, E. A., Aguileta, M. A., McLelland, G. L., et al. (2014). USP8 regulates mitophagy by removing K6linked ubiquitin conjugates from parkin. EMBO J. 33, 2473-2491. doi: 10. 15252/embj.201489729

Dynek, J. N., Goncharov, T., Dueber, E. C., Fedorova, A. V., Izrael-Tomasevic, A., Phu, L., et al. (2010). c-IAP1 and UbcH5 promote K11-linked polyubiquitination of RIP1 in TNF signalling. EMBO J. 29, 4198-4209. doi: 10.1038/emboj.2010.300

Ecker, D. J., Khan, M. I., Marsh, J., Butt, T. R., and Crooke, S. T. (1987). Chemical synthesis and expression of a cassette adapted ubiquitin gene. J. Biol. Chem. 262, 3524-3527.

Eddins, M. J., Carlile, C. M., Gomez, K. M., Pickart, C. M., and Wolberger, C. (2006). Mms2-Ubc13 covalently bound to ubiquitin reveals the structural basis of linkage-specific polyubiquitin chain formation. Nat. Struct. Mol. Biol. 13, 915-920. doi: 10.1038/nsmb1148

Elia, A. E., Boardman, A. P., Wang, D. C., Huttlin, E. L., Everley, R. A., Dephoure, N., et al. (2015). Quantitative proteomic atlas of ubiquitination and acetylation in the DNA damage response. Mol. Cell 59, 867-881. doi: 10.1016/j.molcel. 2015.05.006

Emmerich, C. H., Ordureau, A., Strickson, S., Arthur, J. S., Pedrioli, G., Komander, D., et al. (2013). Activation of the canonical IKK complex by K63/M1-linked hybrid ubiquitin chains. Proc. Natl. Acad. Sci. U.S.A. 110, 15247-15252. doi: 10.1073/pnas. 1314715110

Fei, C., Li, Z., Li, C., Chen, Y., Chen, Z., He, X., et al. (2013). Smurf1-mediated Lys29-linked nonproteolytic polyubiquitination of axin negatively regulates Wnt/ $\beta$-catenin signaling. Mol. Cell Biol. 33, 4095-4105. doi: 10.1128/mcb. 00418-13

Feng, X., Jia, Y., Zhang, Y., Ma, F., Zhu, Y., Hong, X., et al. (2019). Ubiquitination of UVRAG by SMURF1 promotes autophagosome maturation and inhibits hepatocellular carcinoma growth. Autophagy 15, 1130-1149. doi: 10.1080/ 15548627.2019.1570063

Flick, K., Raasi, S., Zhang, H., Yen, J. L., and Kaiser, P. (2006). A ubiquitininteracting motif protects polyubiquitinated Met 4 from degradation by the $26 \mathrm{~S}$ proteasome. Nat. Cell Biol. 8, 509-515. doi: 10.1038/ncb1402

Fornace, A. J., Alamo, I., Hollander, M. C., and Lamoreaux, E. (1989). Ubiquitin mRNA is a major stress-induced transcript in mammalian cells. Nucleic Acids Res. 17, 1215-1230. doi: 10.1093/nar/17.3.1215

Freudenthal, B. D., Gakhar, L., Ramaswamy, S., and Washington, M. T. (2010). Structure of monoubiquitinated PCNA and implications for translesion synthesis and DNA polymerase exchange. Nat. Struct. Mol. Biol. 17, 479-484. doi: $10.1038 / \mathrm{nsmb} .1776$

Gack, M. U., Shin, Y. C., Joo, C. H., Urano, T., Liang, C., Sun, L., et al. (2007). TRIM25 RING-finger E3 ubiquitin ligase is essential for RIG-I-mediated antiviral activity. Nature 446, 916-920. doi: 10.1038/nature05732

García-Caballero, A., Gadotti, V. M., Stemkowski, P., Weiss, N., Souza, I. A., Hodgkinson, V., et al. (2014). The deubiquitinating enzyme USP5 modulates neuropathic and inflammatory pain by enhancing Cav3.2 channel activity. Neuron 83, 1144-1158. doi: 10.1016/j.neuron.2014.07.036

García-Caballero, A., Gadotti, V. M., Chen, L., and Zamponi, G. W. (2016). A cell-permeant peptide corresponding to the cUBP domain of USP5 reverses inflammatory and neuropathic pain. Mol. Pain 12:1744806916642444. doi: 10. $1177 / 1744806916642444$

Garnett, M. J., Mansfeld, J., Godwin, C., Matsusaka, T., Wu, J., Russell, P., et al. (2009). UBE2S elongates ubiquitin chains on APC/C substrates to promote mitotic exit. Nat. Cell. Biol. 11, 1363-1369. doi: 10.1038/ncb1983

Gatti, M., Pinato, S., Maiolica, A., Rocchio, F., Prato, M. G., Aebersold, R., et al. (2015). RNF168 promotes noncanonical K27 ubiquitination to signal DNA damage. Cell Rep. 10, 226-238. doi: 10.1016/j.celrep.2014.12.021

Geisler, S., Holmström, K. M., Skujat, D., Fiesel, F. C., Rothfuss, O. C., Kahle, P. J., et al. (2010). PINK1/Parkin-mediated mitophagy is dependent on VDAC1 and p62/SQSTM1. Nat. Cell Biol. 12, 119-131. doi: 10.1038/ncb2012

Gerlach, B., Cordier, S. M., Schmukle, A. C., Emmerich, C. H., Rieser, E., Haas, T. L., et al. (2011). Linear ubiquitination prevents inflammation and regulates immune signalling. Nature 471, 591-596. doi: 10.1038/nature09816

Gomez-Diaz, C., and Ikeda, F. (2019). Roles of ubiquitin in autophagy and cell death. Semin Cell Dev. Biol. 93, 125-135. doi: 10.1016/j.semcdb.2018.09.004 
Grice, G. L., Lobb, I. T., Weekes, M. P., Gygi, S. P., Antrobus, R., and Nathan, J. A. (2015). The Proteasome Distinguishes between Heterotypic and Homotypic Lysine-11-Linked Polyubiquitin Chains. Cell Rep. 12, 545-553. doi: 10.1016/ j.celrep.2015.06.061

Gu, H., Shi, X., Liu, C., Wang, C., Sui, N., Zhao, Y., et al. (2019). USP8 maintains embryonic stem cell stemness via deubiquitination of EPG5. Nat. Commu. 10:1465.

Hadari, T., Warms, J. V., Rose, I. A., and Hershko, A. (1992). A ubiquitin C-terminal isopeptidase that acts on polyubiquitin chains. role in protein degradation. J. Biol. Chem. 267, 719-727.

Hage, A., and Rajsbaum, R. (2019). To TRIM or not to TRIM: the balance of host-virus interactions mediated by the ubiquitin system. J. Gen. Virol. 100, 1641-1662. doi: 10.1099/jgv.0.001341

Hao, R., Nanduri, P., Rao, Y., Panichelli, R. S., Ito, A., Yoshida, M., et al. (2013). Proteasomes activate aggresome disassembly and clearance by producing unanchored ubiquitin chains. Mol. Cell 51, 819-828. doi: 10.1016/j.molcel. 2013.08.016

Harper, J. W., Ordureau, A., and Heo, J. M. (2018). Building and decoding ubiquitin chains for mitophagy. Nat. Rev. Mol. Cell. Biol. 19, 93-108. doi: 10.1038/nrm.2017.129

Hershko, A., and Ciechanover, A. (1998). The ubiquitin system. Annu. Rev. Biochem. 67, 425-479.

Hibbert, R. G., Huang, A., Boelens, R., and Sixma, T. K. (2011). E3 ligase Rad18 promotes monoubiquitination rather than ubiquitin chain formation by E2 enzyme Rad6. Proc. Natl. Acad. Sci. U.S.A. 108, 5590-5595. doi: 10.1073/pnas. 1017516108

Hicke, L., Schubert, H. L., and Hill, C. P. (2005). Ubiquitin-binding domains. Nat. Rev. Mol. Cell Biol. 6, 610-621.

Hodgins, R. R., Ellison, K. S., and Ellison, M. J. (1992). Expression of a ubiquitin derivative that conjugates to protein irreversibly produces phenotypes consistent with a ubiquitin deficiency. J. Biol. Chem. 267, 8807-8812.

Hoege, C., Pfander, B., Moldovan, G. L., Pyrowolakis, G., and Jentsch, S. (2002). RAD6-dependent DNA repair is linked to modification of PCNA by ubiquitin and SUMO. Nature 419, 135-141. doi: 10.1038/nature00991

Hoeller, D., Crosetto, N., Blagoev, B., Raiborg, C., Tikkanen, R., Wagner, S., et al. (2006). Regulation of ubiquitin-binding proteins by monoubiquitination. Nat. Cell Biol. 8, 163-169. doi: 10.1038/ncb1354

Hoeller, D., Hecker, C. M., Wagner, S., Rogov, V., Dötsch, V., and Dikic, I. (2007). E3-independent monoubiquitination of ubiquitin-binding proteins. Mol. Cell. 26, 891-898. doi: 10.1016/j.molcel.2007.05.014

Hospenthal, M. K., Freund, S. M., and Komander, D. (2013). Assembly, analysis and architecture of atypical ubiquitin chains. Nat. Struct. Mol. Biol. 20, 555-565. doi: $10.1038 / \mathrm{nsmb} .2547$

Hou, F., Sun, L., Zheng, H., Skaug, B., Jiang, Q. X., and Chen, Z. J. (2011). MAVS forms functional prion-like aggregates to activate and propagate antiviral innate immune response. Cell 146, 448-461. doi: 10.1016/j.cell.2011.06.041

Huang, F., Zeng, X., Kim, W., Balasubramani, M., Fortian, A., Gygi, S. P., et al. (2013). Lysine 63-linked polyubiquitination is required for EGF receptor degradation. Proc. Natl. Acad. Sci. U.S.A. 110, 15722-15727. doi: 10.1073/pnas. 1308014110

Huang, H., Jeon, M. S., Liao, L., Yang, C., Elly, C., Yates, J. R., et al. (2010). K33-linked polyubiquitination of $\mathrm{T}$ cell receptor-zeta regulates proteolysisindependent T cell signaling. Immunity 33, 60-70. doi: 10.1016/j.immuni.2010. 07.002

Huang, J., Huen, M. S., Kim, H., Leung, C. C., Glover, J. N., Yu, X., et al. (2009). RAD18 transmits DNA damage signalling to elicit homologous recombination repair. Nat. Cell Biol. 11, 592-603. doi: 10.1038/ncb1865

Huang, M., and D'Andrea, A. D. (2010). A new nuclease member of the FAN club. Nat. Struct. Mol. Biol. 17, 926-928. doi: 10.1038/nsmb0810-926

Huang, T. T., Nijman, S. M., Mirchandani, K. D., Galardy, P. J., Cohn, M. A., Haas, W., et al. (2006). Regulation of monoubiquitinated PCNA by DUB autocleavage. Nat. Cell Biol. 8, 339-347.

Hwang, C. S., Shemorry, A., Auerbach, D., and Varshavsky, A. (2010). The N-end rule pathway is mediated by a complex of the RING-type Ubr1 and HECTtype Ufd4 ubiquitin ligases. Nat. Cell Biol. 12, 1177-1185. doi: 10.1038/ncb 2121

Ikeda, F., Deribe, Y. L., Skånland, S. S., Stieglitz, B., Grabbe, C., Franz-Wachtel, M., et al. (2011). SHARPIN forms a linear ubiquitin ligase complex regulating
NF-кB activity and apoptosis. Nature 471, 637-641. doi: 10.1038/nature 09814

Inn, K. S., Gack, M. U., Tokunaga, F., Shi, M., Wong, L. Y., Iwai, K., et al. (2011). Linear ubiquitin assembly complex negatively regulates RIG-I- and TRIM25mediated type I interferon induction. Mol. Cell 41, 354-365. doi: 10.1016/j. molcel.2010.12.029

Ishikawa, H., Ma, Z., and Barber, G. N. (2009). STING regulates intracellular DNAmediated, type I interferon-dependent innate immunity. Nature 461, 788-792. doi: $10.1038 /$ nature 08476

Jiang, X., Kinch, L. N., Brautigam, C. A., Chen, X., Du, F., Grishin, N. V., et al. (2012). Ubiquitin-induced oligomerization of the RNA sensors RIG-I and MDA5 activates antiviral innate immune response. Immunity 36, 959-973. doi: 10.1016/j.immuni.2012.03.022

Jin, L., Pahuja, K. B., Wickliffe, K. E., Gorur, A., Baumgärtel, C., Schekman, R., et al. (2012). Ubiquitin-dependent regulation of COPII coat size and function. Nature 482, 495-500. doi: 10.1038/nature10822

Jin, L., Williamson, A., Banerjee, S., Philipp, I., and Rape, M. (2008). Mechanism of ubiquitin-chain formation by the human anaphase-promoting complex. Cell 133, 653-665. doi: 10.1016/j.cell.2008.04.012

Joachim, J., Razi, M., Judith, D., Wirth, M., Calamita, E., Encheva, V., et al. (2017). Centriolar satellites control GABARAP Ubiquitination and GABARAPMediated autophagy. Curr Biol. 27, 2123-2136.e7.

Johnson, E. S., Ma, P. C., Ota, I. M., and Varshavsky, A. (1995). A proteolytic pathway that recognizes ubiquitin as a degradation signal. J. Biol. Chem. 270, 17442-17456. doi: 10.1074/jbc.270.29.17442

Joo, W., Xu, G., Persky, N. S., Smogorzewska, A., Rudge, D. G., Buzovetsky, O., et al. (2011). Structure of the FANCI-FANCD2 complex: insights into the Fanconi anemia DNA repair pathway. Science 333, 312-316. doi: 10.1126/ science. 1205805

Kaiser, S. E., Riley, B. E., Shaler, T. A., Trevino, R. S., Becker, C. H., Schulman, H., et al. (2011). Protein standard absolute quantification (PSAQ) method for the measurement of cellular ubiquitin pools. Nat. Methods 8, 691-696. doi: 10.1038/nmeth.1649

Kensche, T., Tokunaga, F., Ikeda, F., Goto, E., Iwai, K., and Dikic, I. (2012). Analysis of nuclear factor-kappaB (NF-kappaB) essential modulator (NEMO) binding to linear and lysine-linked ubiquitin chains and its role in the activation of NF-kappaB. J. Biol. Chem. 287, 23626-23634. doi: 10.1074/jbc.m112.34 7195

Kim, H. C., and Huibregtse, J. M. (2009). Polyubiquitination by HECT E3s and the determinants of chain type specificity. Mol. Cell Biol. 29, 3307-3318. doi: 10.1128/mcb.00240-09

Kim, H. T., Kim, K. P., Lledias, F., Kisselev, A. F., Scaglione, K. M., Skowyra, D., et al. (2007). Certain pairs of ubiquitin-conjugating enzymes (E2s) and ubiquitin-protein ligases (E3s) synthesize nondegradable forked ubiquitin chains containing all possible isopeptide linkages. J. Biol. Chem. 282, 1737517386. doi: 10.1074/jbc.m609659200

Kim, W., Bennett, E. J., Huttlin, E. L., Guo, A., Li, J., Possemato, A., et al. (2011). Systematic and quantitative assessment of the ubiquitin-modified proteome. Mol. Cell. 44, 325-340. doi: 10.1016/j.molcel.2011.08.025

Kirisako, T., Kamei, K., Murata, S., Kato, M., Fukumoto, H., Kanie, M., et al. (2006). A ubiquitin ligase complex assembles linear polyubiquitin chains. EMBO J. 25, 4877-4887. doi: 10.1038/sj.emboj.7601360

Kirkin, V., McEwan, D. G., Novak, I., and Dikic, I. (2009). A role for ubiquitin in selective autophagy. Mol. Cell 34, 259-269. doi: 10.1016/j.molcel.2009. 04.026

Kirkpatrick, D. S., Hathaway, N. A., Hanna, J., Elsasser, S., Rush, J., Finley, D., et al. (2006). Quantitative analysis of in vitro ubiquitinated cyclin B1 reveals complex chain topology. Nat. Cell Biol. 8, 700-710. doi: 10.1038/ncb1436

Koegl, M., Hoppe, T., Schlenker, S., Ulrich, H. D., Mayer, T. U., and Jentsch, S. (1999). A novel ubiquitination factor, E4, is involved in multiubiquitin chain assembly. Cell 96, 635-644. doi: 10.1016/s0092-8674(00)80574-7

Komander, D., Clague, M. J., and Urbe, S. (2009). Breaking the chains: structure and function of the deubiquitinases. Nat. Rev. Mol. Cell Biol. 10, 550-563. doi: $10.1038 / \mathrm{nrm} 2731$

Komander, D., and Rape, M. (2012). The ubiquitin code. Annu. Rev. Biochem. 81, 203-229.

Kovacs, L., Nagy, O., Pal, M., Udvardy, A., Popescu, O., and Deak. (2015). Role of the deubiquitylating enzyme DmUsp5 in coupling ubiquitin equilibrium to 
development and apoptosis in Drosophila melanogaster. PLoS One 10:e0120875. doi: 10.1371/journal.pone. 0120875

Kristariyanto, Y. A., Abdul Rehman, S. A., Campbell, D. G., Morrice, N. A., Johnson, C., Toth, R., et al. (2015a). K29-selective ubiquitin binding domain reveals structural basis of specificity and heterotypic nature of k29 polyubiquitin. Mol. Cell 58, 83-94. doi: 10.1016/j.molcel.2015.01.041

Kristariyanto, Y. A., Choi, S. Y., Rehman, S. A., Ritorto, M. S., Campbell, D. G., Morrice, N. A., et al. (2015b). Assembly and structure of Lys33-linked polyubiquitin reveals distinct conformations. Biochem. J. 467, 345-352. doi: 10.1042/bj20141502

Kwasna, D., Abdul Rehman, S. A., Natarajan, J., Matthews, S., Madden, R., De Cesare, V., et al. (2018). Discovery and Characterization of ZUFSP/ZUP1, a Distinct Deubiquitinase Class Important for Genome Stability. Mol. Cell 70,150-164.e6.

Lam, Y. A., Xu, W., DeMartino, G. N., and Cohen, R. E. (1997). Editing of ubiquitin conjugates by an isopeptidase in the $26 \mathrm{~S}$ proteasome. Nature $385,737-740$. doi: $10.1038 / 385737 \mathrm{a} 0$

Laplantine, E., Fontan, E., Chiaravalli, J., Lopez, T., Lakisic, G., Veron, M., et al. (2009). NEMO specifically recognizes K63-linked poly-ubiquitin chains through a new bipartite ubiquitin-binding domain. EMBO J. 28, 2885-2895. doi: 10.1038/emboj.2009.241

Lauwers, E., Jacob, C., and André, B. (2009). K63-linked ubiquitin chains as a specific signal for protein sorting into the multivesicular body pathway. J. Cell Biol. 185, 493-502. doi: $10.1083 /$ jcb.200810114

Lee, B. H., Lu, Y., Prado, M. A., Shi, Y., Tian, G., Sun, S., et al. (2016). USP14 deubiquitinates proteasome-bound substrates that are ubiquitinated at multiple sites. Nature 532, 398-401. doi: 10.1038/nature17433

Li, W., Tu, D., Brunger, A. T., and Ye, Y. (2007). A ubiquitin ligase transfers preformed polyubiquitin chains from a conjugating enzyme to a substrate. Nature 446, 333-337. doi: 10.1038/nature05542

Liang, J. R., Martinez, A., Lane, J. D., Mayor, U., Clague, M. J., and Urbé, S. (2015). USP30 deubiquitylates mitochondrial Parkin substrates and restricts apoptotic cell death. EMBO Rep. 16, 618-627. doi: 10.15252/embr.201439820

Lin, D. Y., Diao, J., Zhou, D., and Chen, J. (2011). Biochemical and structural studies of a HECT-like ubiquitin ligase from Escherichia coli O157:H7. J. Biol. Chem. 286, 441-449. doi: 10.1074/jbc.m110.167643

Liu, J., Han, C., Xie, B., Wu, Y., Liu, S., Chen, K., et al. (2014a). Rhbdd3 controls autoimmunity by suppressing the production of IL-6 by dendritic cells via K27-linked ubiquitination of the regulator NEMO. Nat. Immunol. 15, 612-622. doi: $10.1038 /$ ni.2898

Liu, Z., Chen, P., Gao, H., Gu, Y., Yang, J., Peng, H., et al. (2014b). Finley, and $\mathrm{Hu}, \mathrm{R}$., ubiquitylation of autophagy receptor optineurin by HACE1 activates selective autophagy for tumor suppression. Cancer Cell 26, 106-120. doi: 10. 1016/j.ccr.2014.05.015

Liu, N., Huang, H., Dou, Q. P., and Liu, J. (2015). Inhibition of 19 S proteasomeassociated deubiquitinases by metal-containing compounds. Oncoscience 2, 457-466. doi: 10.18632/oncoscience. 167

Loo, Y. M., and Gale, M., Jr. (2011). Immune signaling by RIG-I-like receptors. Immunity 34, 680-692. doi: 10.1016/j.immuni.2011.05.003

Lu, Y., Lee, B. H., King, R. W., Finley, D., and Kirschner, M. W. (2015). Substrate degradation by the proteasome: a single-molecule kinetic analysis. Science 348:1250834. doi: 10.1126/science.1250834

Machida, Y. J., Machida, Y., Chen, Y., Gurtan, A. M., Kupfer, G. M., D’Andrea, A. D., et al. (2006). UBE2T is the E2 in the Fanconi anemia pathway and undergoes negative autoregulation. Mol. Cell 23, 589-596. doi: 10.1016/j. molcel.2006.06.024

Margottin-Goguet, F., Hsu, J. Y., Loktev, A., Hsieh, H. M., Reimann, J. D., and Jackson, P. K. (2003). Prophase destruction of Emil by the SCF(betaTrCP/Slimb) ubiquitin ligase activates the anaphase promoting complex to allow progression beyond prometaphase. Dev. Cell 4, 813-826. doi: 10.1016/s1534-5807(03)00153-9

Maspero, E., Mari, S., Valentini, E., Musacchio, A., Fish, A., Pasqualato, S., et al. (2011). Structure of the HECT:ubiquitin complex and its role in ubiquitin chain elongation. EMBO Rep. 12, 342-349. doi: 10.1038/embor.2011.21

Masuda, Y., Suzuki, M., Kawai, H., Hishiki, A., Hashimoto, H., Masutani, C., et al. (2012). En bloc transfer of polyubiquitin chains to PCNA in vitro is mediated by two different human E2-E3 pairs. Nucleic Acids Res. 40, 10394-10407. doi: $10.1093 /$ nar/gks763
Matsumoto, M. L., Wickliffe, K. E., Dong, K. C., Yu, C., Bosanac, I., Bustos, D., et al. (2010). K11-linked polyubiquitination in cell cycle control revealed by a K11 linkage-specific antibody. Mol. Cell 39, 477-484. doi: 10.1016/j.molcel.2010. 07.001

McEwan, W. A., Tam, J. C., Watkinson, R. E., Bidgood, S. R., Mallery, D. L., and James, L. C. (2013). Intracellular antibody-bound pathogens stimulate immune signaling via the Fc receptor TRIM21. Nat. Immunol. 14, 327-336. doi: 10.1038/ni.2548

Mevissen, T. E., Hospenthal, M. K., Geurink, P. P., Elliott, P. R., Akutsu, M., Arnaudo, N., et al. (2013). OTU deubiquitinases reveal mechanisms of linkage specificity and enable ubiquitin chain restriction analysis. Cell 154, 169-184. doi: 10.1016/j.cell.2013.05.046

Meyer, H. J., and Rape, M. (2014). Enhanced protein degradation by branched ubiquitin chains. Cell 157, 910-921. doi: 10.1016/j.cell.2014.03.037

Michel, M. A., Elliott, P. R., Swatek, K. N., Simicek, M., Pruneda, J. N., Wagstaff, J. L., et al. (2015). Assembly and specific recognition of k29- and k33-linked polyubiquitin. Mol. Cell 58, 95-109. doi: 10.1016/j.molcel.2015. 01.042

Min, M., Mevissen, T. E., De Luca, M., Komander, D., and Lindon, C. (2015). Efficient APC/C substrate degradation in cells undergoing mitotic exit depends on K11 ubiquitin linkages. Mol. Biol. Cell 26, 4325-4332. doi: 10.1091/mbc.e1502-0102

Moldovan, G. L., and D'Andrea, A. D. (2009). How the fanconi anemia pathway guards the genome. Annu. Rev. Genet. 43, 223-249. doi: 10.1146/annurevgenet-102108-134222

Moldovan, G. L., Pfander, B., and Jentsch, S. (2007). PCNA, the maestro of the replication fork. Cell 129, 665-679. doi: 10.1016/j.cell.2007.05.003

Moniz, S., Bandarra, D., Biddlestone, J., Campbell, K. J., Komander, D., Bremm, A., et al. (2015). Cezanne regulates E2F1-dependent HIF2 $\alpha$ expression. J. Cell Sci. 128, 3082-3093. doi: $10.1242 /$ jcs. 168864

Morris, J. R., and Solomon, E. (2004). BRCA1 : BARD1 induces the formation of conjugated ubiquitin structures, dependent on K6 of ubiquitin, in cells during DNA replication and repair. Hum. Mol. Genet. 13, 807-817. doi: 10.1093/hmg/ ddh095

Mukhopadhyay, D., and Riezman, H. (2007). Proteasome-independent functions of ubiquitin in endocytosis and signaling. Science 315, 201-205. doi: 10.1126/ science. 1127085

Myllymaki, H., Valanne, S., and Ramet, M. (2014). The Drosophila imd signaling pathway. J. Immunol. 192, 3455-3462. doi: 10.4049/jimmunol.1303309

Nanduri, P., Hao, R., Fitzpatrick, T., and Yao, T. (2015). Chaperone-mediated $26 \mathrm{~S}$ proteasome remodeling facilitates free K63 ubiquitin chain production and aggresome clearance. J. Biol. Chem. 290, 9455-9464. doi: 10.1074/jbc.m114. 627950

Nazio, F., Strappazzon, F., Antonioli, M., Bielli, P., Cianfanelli, V., Bordi, M., et al. (2013). mTOR inhibits autophagy by controlling ULK1 ubiquitylation, selfassociation and function through AMBRA1 and TRAF6. Nat. Cell Biol. 15, 406-416. doi: $10.1038 /$ ncb2708

Nijman, S. M., Huang, T. T., Dirac, A. M., Brummelkamp, T. R., Kerkhoven, R. M., D'Andrea, A. D., et al. (2005). The deubiquitinating enzyme USP1 regulates the Fanconi anemia pathway. Mol. Cell 17, 331-339. doi: 10.1016/j.molcel.2005.01. 008

Nishikawa, H., Ooka, S., Sato, K., Arima, K., Okamoto, J., Klevit, R. E., et al. (2004). Mass spectrometric and mutational analyses reveal Lys-6-linked polyubiquitin chains catalyzed by BRCA1-BARD1 ubiquitin ligase. J. Biol. Chem. 279, 39163924. doi: $10.1074 / \mathrm{jbc} . \mathrm{m} 308540200$

Oh, E., Akopian, D., and Rape, M. (2018). Principles of ubiquitin-dependent signaling. Annu. Rev. Cell Dev. Biol. 34, 137-162. doi: 10.1146/annurev-cellbio100617-062802

Ohtake, F., Tsuchiya, H., Saeki, Y., and Tanaka, K. (2018). K63 ubiquitylation triggers proteasomal degradation by seeding branched ubiquitin chains. Proc. Natl. Acad. Sci. U.S.A. 115, E1401-E1408.

Ordureau, A., Heo, J. M., Duda, D. M., Paulo, J. A., Olszewski, J. L., Yanishevski, D., et al. (2015). Defining roles of PARKIN and ubiquitin phosphorylation by PINK1 in mitochondrial quality control using a ubiquitin replacement strategy. Proc. Natl. Acad. Sci. U.S.A. 112, 6637-6642. doi: 10.1073/pnas.150659 3112

Ordureau, A., Sarraf, S. A., Duda, D. M., Heo, J. M., Jedrychowski, M. P., Sviderskiy, V. O., et al. (2014). Quantitative proteomics reveal a feedforward mechanism 
for mitochondrial PARKIN translocation and ubiquitin chain synthesis. Mol. Cell 56, 360-375. doi: 10.1016/j.molcel.2014.09.007

Osterwalder, T., Yoon, K. S., White, B. H., and Keshishian, H. (2001). A conditional tissue-specific transgene expression system using inducible GAL4. Proc. Natl. Acad. Sci. U.S.A. 98, 12596-12601. doi: 10.1073/pnas.221303298

Ouyang, H., Ali, Y. O., Ravichandran, M., Dong, A., Qiu, W., MacKenzie, F., et al. (2012). Protein aggregates are recruited to aggresome by histone deacetylase 6 via unanchored ubiquitin C termini. J. Biol. Chem. 287, 2317-2327. doi: $10.1074 /$ jbc.m111.273730

Palicharla, V. R., and Maddika, S. (2015). HACE1 mediated K27 ubiquitin linkage leads to YB-1 protein secretion. Cell Signal 27, 2355-2362. doi: 10.1016/j.cellsig. 2015.09.001

Paz, S., Sun, Q., Nakhaei, P., Romieu-Mourez, R., Goubau, D., Julkunen, I., et al. (2006). Induction of IRF-3 and IRF-7 phosphorylation following activation of the RIG-I pathway. Cell Mol. Biol. (Noisy-le-grand) 52, 17-28.

Peisley, A., Wu, B., Xu, H., Chen, Z. J., and Hur, S. (2014). Structural basis for ubiquitin-mediated antiviral signal activation by RIG-I. Nature 509, 110-114. doi: $10.1038 /$ nature 13140

Pertel, T., Hausmann, S., Morger, D., Zuger, S., Guerra, J., Lascano, J., et al. (2011). TRIM5 is an innate immune sensor for the retrovirus capsid lattice. Nature 472, 361-365. doi: 10.1038/nature09976

Petroski, M. D., and Deshaies, R. J. (2005). Mechanism of lysine 48-linked ubiquitin-chain synthesis by the cullin-RING ubiquitin-ligase complex SCFCdc34. Cell 123, 1107-1120. doi: 10.1016/j.cell.2005.09.033

Pickart, C. M., and Rose, I. A. (1985). Ubiquitin carboxyl-terminal hydrolase acts on ubiquitin carboxyl-terminal amides. J. Biol. Chem. 260, 7903-7910.

Piotrowski, J., Beal, R., Hoffman, L., Wilkinson, K. D., Cohen, R. E., and Pickart, C. M. (1997). Inhibition of the $26 \mathrm{~S}$ proteasome by polyubiquitin chains synthesized to have defined lengths. J. Biol. Chem. 272, 23712-23721. doi: $10.1074 / \mathrm{jbc} .272 .38 .23712$

Polo, S., Sigismund, S., Faretta, M., Guidi, M., Capua, M. R., Bossi, G., et al. (2002). A single motif responsible for ubiquitin recognition and monoubiquitination in endocytic proteins. Nature 416, 451-455. doi: 10.1038/416451a

Qin, Y., Zhou, M. T., Hu, M. M., Hu, Y. H., Zhang, J., Guo, L., et al. (2014). RNF26 temporally regulates virus-triggered type I interferon induction by two distinct mechanisms. PLoS Pathog. 10:e1004358. doi: 10.1371/journal.ppat.100 4358

Rahighi, S., Ikeda, F., Kawasaki, M., Akutsu, M., Suzuki, N., Kato, R., et al. (2009). Specific recognition of linear ubiquitin chains by NEMO is important for NF-kappaB activation. Cell 136, 1098-1109. doi: 10.1016/j.cell.2009.03.007

Raiborg, C., and Stenmark, H. (2009). The ESCRT machinery in endosomal sorting of ubiquitylated membrane proteins. Nature 458, 445-452. doi: 10. 1038/nature07961

Rajsbaum, R., Versteeg, G. A., Schmid, S., Maestre, A. M., Belicha-Villanueva, A., Martinez-Romero, C., et al. (2014). Unanchored K48-linked polyubiquitin synthesized by the E3-ubiquitin ligase TRIM6 stimulates the interferonIKKepsilon kinase-mediated antiviral response. Immunity 40, 880-895. doi: 10.1016/j.immuni.2014.04.018

Ren, X., and Hurley, J. H. (2010). VHS domains of ESCRT-0 cooperate in highavidity binding to polyubiquitinated cargo. EMBO J. 29, 1045-1054. doi: 10 . 1038/emboj.2010.6

Reyes-Turcu, F. E., Horton, J. R., Mullally, J. E., Heroux, A., Cheng, X., and Wilkinson, K. D. (2006). The ubiquitin binding domain ZnF UBP recognizes the C-terminal diglycine motif of unanchored ubiquitin. Cell 124, 1197-1208. doi: 10.1016/j.cell.2006.02.038

Reyes-Turcu, F. E., Shanks, J. R., Komander, D., and Wilkinson, K. D. (2008). Recognition of polyubiquitin isoforms by the multiple ubiquitin binding modules of isopeptidase T. J. Biol. Chem. 283, 19581-19592. doi: 10.1074/jbc. m800947200

Richly, H., Rape, M., Braun, S., Rumpf, S., Hoege, C., and Jentsch, S. (2005). A series of ubiquitin binding factors connects CDC48/p97 to substrate multiubiquitylation and proteasomal targeting. Cell 120, 73-84. doi: 10.1016/j. cell.2004.11.013

Ristic, G., Tsou, W. L., Guzi, E., Kanack, A. J., Scaglione, K. M., and Todi, S. V. (2016). USP5 Is dispensable for monoubiquitin maintenance in Drosophila. J. Biol. Chem. 291, 9161-9172. doi: 10.1074/jbc.m115.703504
Rivkin, E., Almeida, S. M., Ceccarelli, D. F., Juang, Y. C., MacLean, T. A., Srikumar, $\mathrm{T}$., et al. (2013). The linear ubiquitin-specific deubiquitinase gumby regulates angiogenesis. Nature 498, 318-324. doi: 10.1038/nature12296

Rodrigo-Brenni, M. C., Foster, S. A., and Morgan, D. O. (2010). Catalysis of lysine 48 -specific ubiquitin chain assembly by residues in E2 and ubiquitin. Mol. Cell 39, 548-559. doi: 10.1016/j.molcel.2010.07.027

Rodriguez-Gonzalez, A., Lin, T., Ikeda, A. K., Simms-Waldrip, T., Fu, C., and Sakamoto, K. M. (2008). Role of the aggresome pathway in cancer: targeting histone deacetylase 6-dependent protein degradation. Cancer Res. 68, 25572560. doi: 10.1158/0008-5472.can-07-5989

Roman, G., Endo, K., Zong, L., and Davis, R. L. (2001). P[Switch], a system for spatial and temporal control of gene expression in Drosophila melanogaster. Proc. Natl. Acad. Sci. U.S.A. 98, 12602-12607. doi: 10.1073/pnas.221303998

Sadowski, M., Suryadinata, R., Lai, X., Heierhorst, J., and Sarcevic, B. (2010). Molecular basis for lysine specificity in the yeast ubiquitin-conjugating enzyme Cdc34. Mol. Cell Biol. 30, 2316-2329. doi: 10.1128/mcb.01094-09

Saeki, Y., Tayama, Y., Toh-e, A., and Yokosawa, H. (2004). Definitive evidence for Ufd2-catalyzed elongation of the ubiquitin chain through Lys48 linkage. Biochem. Biophys. Res. Commun. 320, 840-845. doi: 10.1016/j.bbrc.2004.05.216

Sanchez, J. G., Chiang, J. J., Sparrer, K. M. J., Alam, S. L., Chi, M., et al. (2016). Mechanism of TRIM25 catalytic activation in the antiviral RIG-I pathway. Cell Rep. 16, 1315-1325. doi: 10.1016/j.celrep.2016.06.070

Sarraf, S. A., Raman, M., Guarani-Pereira, V., Sowa, M. E., Huttlin, E. L., Gygi, S. P., et al. (2013). Landscape of the PARKIN-dependent ubiquitylome in response to mitochondrial depolarization. Nature 496, 372-376. doi: 10.1038/nature1 2043

Sato, Y., Goto, E., Shibata, Y., Kubota, Y., Yamagata, A., Goto-Ito, S., et al. (2015). Structures of CYLD USP with Met1- or Lys63-linked diubiquitin reveal mechanisms for dual specificity. Nat. Struct. Mol. Biol. 22, 222-229. doi: 10. 1038/nsmb. 2970

Scaglione, K. M., Zavodszky, E., Todi, S. V., Patury, S., Xu, P., Rodriguez-Lebron, E., et al. (2011). Ube $2 \mathrm{w}$ and ataxin-3 coordinately regulate the ubiquitin ligase CHIP. Mol. Cell 43, 599-612. doi: 10.1016/j.molcel.2011.05.036

Scheffner, M., Huibregtse, J. M., Vierstra, R. D., and Howley, P. M. (1993). The HPV-16 E6 and E6-AP complex functions as a ubiquitin-protein ligase in the ubiquitination of p53. Cell 75, 495-505. doi: 10.1016/0092-8674(93)90 384-3

Scrivo, A., Codogno, P., and Bomont. (2019). Gigaxonin E3 ligase governs ATG16L1 turnover to control autophagosome production. Nat. Commun. 10, 780.

Shembade, N., Ma, A., and Harhaj, E. W. (2010). Inhibition of NF-kappaB signaling by A20 through disruption of ubiquitin enzyme complexes. Science 327, 11351139. doi: $10.1126 /$ science. 1182364

Silva, G. M., Finley, D., and Vogel, C. (2015). K63 polyubiquitination is a new modulator of the oxidative stress response. Nat. Struct. Mol. Biol. 22, 116-123. doi: $10.1038 / \mathrm{nsmb} .2955$

Skaug, B., Chen, J., Du, F., He, J., Ma, A., and Chen, Z. J. (2011). Direct, noncatalytic mechanism of IKK inhibition by A20. Mol. Cell 44, 559-571. doi: 10.1016/j. molcel.2011.09.015

Sloper-Mould, K. E., Jemc, J. C., Pickart, C. M., and Hicke, L. (2001). Distinct functional surface regions on ubiquitin. J. Biol. Chem. 276, 30483-30489. doi: 10.1074/jbc.m103248200

Sobhian, B., Shao, G., Lilli, D. R., Culhane, A. C., Moreau, L. A., Xia, B., et al. (2007). RAP80 targets BRCA1 to specific ubiquitin structures at DNA damage sites. Science 316, 1198-1202. doi: 10.1126/science.1139516

Song, E. J., Werner, S. L., Neubauer, J., Stegmeier, F., Aspden, J., Rio, D., et al. (2010). The Prp19 complex and the Usp4Sart3 deubiquitinating enzyme control reversible ubiquitination at the spliceosome. Genes Dev. 24, 1434-1447. doi: 10.1101/gad.1925010

Song, L., and Luo, Z. Q. (2019). Post-translational regulation of ubiquitin signaling. J. Cell Biol. 218, 1776-1786. doi: 10.1083/jcb.201902074

Spence, J., Gali, R. R., Dittmar, G., Sherman, F., Karin, M., and Finley, D. (2000). Cell cycle-regulated modification of the ribosome by a variant multiubiquitin chain. Cell 102, 67-76. doi: 10.1016/s0092-8674(00)00011-8

Spence, J., Sadis, S., Haas, A. L., and Finley, D. (1995). A ubiquitin mutant with specific defects in DNA repair and multiubiquitination. Mol. Cell Biol. 15, 1265-1273. doi: $10.1128 / \mathrm{mcb} \cdot 15.3 .1265$ 
Srinivasan, V., Kriete, A., Sacan, A., and Jazwinski, S. M. (2010). Comparing the yeast retrograde response and NF-kappaB stress responses: implications for aging. Aging Cell 9, 933-941. doi: 10.1111/j.1474-9726.2010.00622.x

Stein, R. L., Chen, Z., and Melandri, F. (1995). Kinetic studies of isopeptidase T: modulation of peptidase activity by ubiquitin. Biochemistry 34, 12616-12623. doi: 10.1021/bi00039a017

Stewart, G. S., Panier, S., Townsend, K., Al-Hakim, A. K., Kolas, N. K., Miller, E. S., et al. (2009). The RIDDLE syndrome protein mediates a ubiquitin-dependent signaling cascade at sites of DNA damage. Cell 136, 420-434. doi: 10.1016/j. cell.2008.12.042

Swatek, K. N., and Komander, D. (2016). Ubiquitin modifications. Cell Res. 26, $399-422$.

Tauriello, D. V., and Maurice, M. M. (2010). The various roles of ubiquitin in Wnt pathway regulation. Cell Cycle 9, 3700-3709.

Tenno, T., Fujiwara, K., Tochio, H., Iwai, K., Morita, E. H., Hayashi, H., et al. (2004). Structural basis for distinct roles of Lys63- and Lys48-linked polyubiquitin chains. Genes Cells 9, 865-875. doi: 10.1111/j.1365-2443.2004. 00780.x

Thrower, J. S., Hoffman, L., Rechsteiner, M., and Pickart, C. M. (2000). Recognition of the polyubiquitin proteolytic signal. EMBO J. 19, 94-102. doi: 10.1093/ emboj/19.1.94

Tokunaga, F., and Iwai, K. (2009). [Involvement of LUBAC-mediated linear polyubiquitination of NEMO in NF-kappaB activation]. Tanpakushitsu Kakusan Koso. 54, 635-642.

Tokunaga, F., Nakagawa, T., Nakahara, M., Saeki, Y., Taniguchi, M., Sakata, S., et al. (2011). SHARPIN is a component of the NF-kB-activating linear ubiquitin chain assembly complex. Nature 471, 633-636. doi: 10.1038/nature 09815

Tokunaga, F., Sakata, S., Saeki, Y., Satomi, Y., Kirisako, T., Kamei, K., et al. (2009). Involvement of linear polyubiquitylation of NEMO in NF-kappaB activation. Nat. Cell Biol. 11, 123-132. doi: 10.1038/ncb1821

Tsou, W. L., Sheedlo, M. J., Morrow, M. E., Blount, J. R., McGregor, K. M., Das, C., et al. (2012). Systematic analysis of the physiological importance of deubiquitinating enzymes. PLoS One 7:e43112. doi: 10.1371/journal.pone. 0043112

Tsuchiya, H., Tanaka, K., and Saeki, Y. (2013). The parallel reaction monitoring method contributes to a highly sensitive polyubiquitin chain quantification. Biochem. Biophys. Res. Commun. 436, 223-229. doi: 10.1016/j.bbrc.2013. 05.080

Valanne, S., Wang, J. H., and Ramet, M. (2011). The Drosophila toll signaling pathway. J. Immunol. 186, 649-656. doi: 10.4049/jimmunol.1002302

Varadan, R., Assfalg, M., Haririnia, A., Raasi, S., Pickart, C., and Fushman, D. (2004). Solution conformation of Lys63-linked di-ubiquitin chain provides clues to functional diversity of polyubiquitin signaling. J. Biol. Chem. 279, 7055-7063. doi: 10.1074/jbc.m309184200

Wagner, S. A., Beli, P., Weinert, B. T., Nielsen, M. L., Cox, J., Mann, M., et al. (2011). A proteome-wide, quantitative survey of in vivo ubiquitylation sites reveals widespread regulatory roles. Mol. Cell Proteom. 10, M111.013284.

Wang, C., Deng, L., Hong, M., Akkaraju, G. R., Inoue, J., and Chen, Z. J. (2001). TAK1 is a ubiquitin-dependent kinase of MKK and IKK. Nature 412, 346-351. doi: 10.1038/35085597

Wang, C. H., Chen, G. C., and Chien, C. T. (2014a). The deubiquitinase Leon/USP5 regulates ubiquitin homeostasis during Drosophila development. Biochem. Biophys. Res. Commun. 452, 369-375. doi: 10.1016/j.bbrc.2014. 08.069

Wang, Q., Liu, X., Cui, Y., Tang, Y., Chen, W., Li, S., et al. (2014b). The E3 ubiquitin ligase AMFR and INSIG1 bridge the activation of TBK1 kinase by modifying the adaptor STING. Immunity 41, 919-933. doi: 10.1016/j.immuni.2014. 11.011

Wang, H., Wang, L., Erdjument-Bromage, H., Vidal, M., Tempst, P., Jones, R. S., et al. (2004). Role of histone H2A ubiquitination in Polycomb silencing. Nature 431, 873-878. doi: 10.1038 /nature02985

Wang, M., Cheng, D., Peng, J., and Pickart, C. M. (2006). Molecular determinants of polyubiquitin linkage selection by an HECT ubiquitin ligase. EMBO J. 25, 1710-1719. doi: 10.1038/sj.emboj.7601061

Wang, M., and Pickart, C. M. (2005). Different HECT domain ubiquitin ligases employ distinct mechanisms of polyubiquitin chain synthesis. EMBO J. 24, 4324-4333. doi: 10.1038/sj.emboj.7600895
Werner, A., Iwasaki, S., McGourty, C. A., Medina-Ruiz, S., Teerikorpi, N., Fedrigo, I., et al. (2015). Cell-fate determination by ubiquitin-dependent regulation of translation. Nature 525, 523-527. doi: 10.1038/nature14978

Wertz, I. E., O’Rourke, K. M., Zhou, H., Eby, M., Aravind, L., Seshagiri, S., et al. (2004). De-ubiquitination and ubiquitin ligase domains of A20 downregulate NF-kappaB signalling. Nature 430, 694-699. doi: 10.1038/nature 02794

Wheeler, J. R., Jain, S., Khong, A., and Parker, R. (2017). Isolation of yeast and mammalian stress granule cores. Methods 126, 12-17. doi: 10.1016/j.ymeth. 2017.04.020

Wickliffe, K. E., Williamson, A., Meyer, H. J., Kelly, A., and Rape, M. (2011). K11linked ubiquitin chains as novel regulators of cell division. Trends Cell Biol. 21, 656-663. doi: 10.1016/j.tcb.2011.08.008

Wigley, W. C., Fabunmi, R. P., Lee, M. G., Marino, C. R., Muallem, S., DeMartino, G. N., et al. (1999). Dynamic association of proteasomal machinery with the centrosome. J. Cell Biol. 145, 481-490. doi: 10.1083/jcb.145.3.481

Wilkinson, K. D., Tashayev, V. L., O'Connor, L. B., Larsen, C. N., Kasperek, E., and Pickart, C. M. (1995). Metabolism of the polyubiquitin degradation signal: structure, mechanism, and role of isopeptidase T. Biochemistry 34, 14535-14546. doi: 10.1021/bi00044a032

Williamson, A., Wickliffe, K. E., Mellone, B. G., Song, L., Karpen, G. H., and Rape, M. (2009). Identification of a physiological E2 module for the human anaphase-promoting complex. Proc. Natl. Acad. Sci. U.S.A. 106, 18213-18218. doi: 10.1073/pnas.0907887106

Winston, J. T., Strack, P., Beer-Romero, P., Chu, C. Y., Elledge, S. J., and Harper, J. W. (1999). The SCFbeta-TRCP-ubiquitin ligase complex associates specifically with phosphorylated destruction motifs in IkappaBalpha and betacatenin and stimulates IkappaBalpha ubiquitination in vitro. Genes Dev. 13, 270-283. doi: 10.1101/gad.13.3.270

Wu, T., Merbl, Y., Huo, Y., Gallop, J. L., Tzur, A., and Kirschner, M. W. (2010). UBE2S drives elongation of K11-linked ubiquitin chains by the anaphasepromoting complex. Proc. Natl. Acad. Sci. U.S.A. 107, 1355-1360. doi: 10.1073/ pnas.0912802107

Wu-Baer, F., Lagrazon, K., Yuan, W., and Baer, R. (2003). The BRCA1/BARD1 heterodimer assembles polyubiquitin chains through an unconventional linkage involving lysine residue K6 of ubiquitin. J. Biol. Chem. 278, 3474334746. doi: 10.1074/jbc.c300249200

Xia, P., Wang, S., Du, Y., Zhao, Z., Shi, L., Sun, L., et al. (2013). WASH inhibits autophagy through suppression of Beclin 1 ubiquitination. EMBO J. 32, 26852696. doi: $10.1038 /$ emboj.2013.189

Xia, P., Wang, S., Huang, G., Du, Y., Zhu, P., Li, M., et al. (2014). RNF2 is recruited by WASH to ubiquitinate AMBRA1 leading to downregulation of autophagy. Cell Res. 24, 943-958. doi: 10.1038/cr.2014.85

Xia, Z. P., Sun, L., Chen, X., Pineda, G., Jiang, X., Adhikari, A., et al. (2009). Direct activation of protein kinases by unanchored polyubiquitin chains. Nature 461, 114-119. doi: 10.1038/nature08247

Xie, X., Matsumoto, S., Endo, A., Fukushima, T., Kawahara, H., Saeki, Y., et al. (2018). Deubiquitylases USP5 and USP13 are recruited to and regulate heatinduced stress granules through their deubiquitylating activities. J. Cell Sci. 131, jcs210856. doi: 10.1242/jcs.210856

Xu, C., Feng, K., Zhao, X., Huang, S., Cheng, Y., Qian, L., et al. (2014). Regulation of autophagy by E3 ubiquitin ligase RNF216 through BECN1 ubiquitination. Autophagy 10, 2239-2250. doi: 10.4161/15548627.2014.981792

Xu, M., Skaug, B., Zeng, W., and Chen, Z. J. (2009a). A ubiquitin replacement strategy in human cells reveals distinct mechanisms of IKK activation by TNFalpha and IL-1beta. Mol. Cell 36, 302-314. doi: 10.1016/j.molcel.2009.10. 002

Xu, P., Duong, D. M., Seyfried, N. T., Cheng, D., Xie, Y., Robert, J., et al. (2009b). Quantitative proteomics reveals the function of unconventional ubiquitin chains in proteasomal degradation. Cell 137, 133-145. doi: 10.1016/j.cell.2009. 01.041

Xu, Z., Kohli, E., Devlin, K. I., Bold, M., Nix, J. C., and Misra, S. (2008). Interactions between the quality control ubiquitin ligase CHIP and ubiquitin conjugating enzymes. BMC Struct. Biol. 8:26. doi: 10.1186/1472-6807-8-26

Yao, T., and Cohen, R. E. (2002). A cryptic protease couples deubiquitination and degradation by the proteasome. Nature 419, 403-407. doi: 10.1038/nature01071

Yau, R., and Rape, M. (2016). The increasing complexity of the ubiquitin code. Nat. Cell Biol. 18, 579-586. doi: 10.1038/ncb3358 
Yau, R. G., Doerner, K., Castellanos, E. R., Haakonsen, D. L., Werner, A., Wang, N., et al. (2017). Assembly and Function of Heterotypic Ubiquitin Chains in Cell-Cycle and Protein Quality Control. Cell 171, 918.e-933.e.

You, J., and Pickart, C. M. (2001). A HECT domain E3 enzyme assembles novel polyubiquitin chains. J. Biol. Chem. 276, 19871-19878. doi: 10.1074/jbc. m100034200

Yuan, W. C., Lee, Y. R., Lin, S. Y., Chang, L. Y., Tan, Y. P., Hung, C. C., et al. (2014). K33-Linked Polyubiquitination of Coronin 7 by Cul3-KLHL20 Ubiquitin E3 Ligase Regulates Protein Trafficking. Mol. Cell. 54, 586-600. doi: 10.1016/j. molcel.2014.03.035

Zeng, W., Sun, L., Jiang, X., Chen, X., Hou, F., Adhikari, A., et al. (2010). Reconstitution of the RIG-I pathway reveals a signaling role of unanchored polyubiquitin chains in innate immunity. Cell 141, 315-330. doi: 10.1016/j.cell. 2010.03.029

Zhang, M., Windheim, M., Roe, S. M., Peggie, M., Cohen, P., Prodromou, C., et al. (2005). Chaperoned ubiquitylation-crystal structures of the CHIP U box E3 ubiquitin ligase and a CHIP-Ubc13-Uevla complex. Mol. Cell 20, 525-538. doi: 10.1016/j.molcel.2005.09.023
Zhou, R., Silverman, N., Hong, M., Liao, D. S., Chung, Y., Chen, Z. J., et al. (2005). The role of ubiquitination in Drosophila innate immunity. J. Biol. Chem. 280, 34048-34055. doi: 10.1074/jbc.m506655200

Ziv, I., Matiuhin, Y., Kirkpatrick, D. S., Erpapazoglou, Z., Leon, S., Pantazopoulou, M., et al. (2011). A perturbed ubiquitin landscape distinguishes between ubiquitin in trafficking and in proteolysis. Mol. Cell Proteom. 10:M111.00 9753.

Conflict of Interest: The authors declare that the research was conducted in the absence of any commercial or financial relationships that could be construed as a potential conflict of interest.

Copyright (C) 2020 Blount, Johnson and Todi. This is an open-access article distributed under the terms of the Creative Commons Attribution License (CC BY). The use, distribution or reproduction in other forums is permitted, provided the original author(s) and the copyright owner(s) are credited and that the original publication in this journal is cited, in accordance with accepted academic practice. No use, distribution or reproduction is permitted which does not comply with these terms. 